

\title{
Relationship between the Ozone and Water Vapor columns on Mars as Observed by SPICAM and Calculated by a Global Climate Model
}

Franck Lefèvre, A. Trokhimovskiy, A. Fedorova, Lucio Baggio, Gaetan Lacombe, Anni Määttänen, Jean-Loup Bertaux, F. Forget, E. Millour, O. Venot, et al.

\section{To cite this version:}

Franck Lefèvre, A. Trokhimovskiy, A. Fedorova, Lucio Baggio, Gaetan Lacombe, et al.. Relationship between the Ozone and Water Vapor columns on Mars as Observed by SPICAM and Calculated by a Global Climate Model. Journal of Geophysical Research. Planets, 2021, 126 (4), pp.e2021JE006838. 10.1029/2021JE006838 . insu-03195382

\section{HAL Id: insu-03195382 https://hal-insu.archives-ouvertes.fr/insu-03195382}

Submitted on 11 Apr 2021

HAL is a multi-disciplinary open access archive for the deposit and dissemination of scientific research documents, whether they are published or not. The documents may come from teaching and research institutions in France or abroad, or from public or private research centers.
L'archive ouverte pluridisciplinaire HAL, est destinée au dépôt et à la diffusion de documents scientifiques de niveau recherche, publiés ou non, émanant des établissements d'enseignement et de recherche français ou étrangers, des laboratoires publics ou privés. 


\section{Relationship between the Ozone and Water Vapor columns on Mars as Observed by SPICAM and Calculated by a Global Climate Model}

F. Lefèvre', A. Trokhimovskiy ${ }^{2}$, A. Fedorova ${ }^{2}$, L. Baggio ${ }^{1}$, G. Lacombe ${ }^{1}$, A. Määttänen ${ }^{1}$, J.-L. Bertaux ${ }^{1}$, F. Forget ${ }^{3}$, E. Millour ${ }^{3}$, O. Venot $^{4}$, Y. Bénilan ${ }^{4}$, O. Korablev ${ }^{2}$, F. Montmessin ${ }^{1}$

${ }^{1}$ LATMOS, Sorbonne Université, UVSQ Université Paris-Saclay, CNRS, Paris, France

${ }^{2}$ Space Research Institute (IKI) RAS, Moscow, Russian Federation

${ }^{3}$ LMD, CNRS, Sorbonne Université, Paris, France

${ }^{4}$ Laboratoire Interuniversitaire des Systèmes Atmosphériques (LISA), UMR CNRS 7583, Université Paris-Est-Créteil, Université de Paris, Institut Pierre Simon Laplace, Créteil, France

Corresponding author: Franck Lefèvre (ranck.lefevre@,latmos.ipsl.fr)

\section{Key Points:}

- The relationship between the $\mathrm{O}_{3}$ and $\mathrm{H}_{2} \mathrm{O}$ columns on Mars is quantified from four Martian years of simultaneous measurements.

- The $\mathrm{O}_{3}$ and $\mathrm{H}_{2} \mathrm{O}$ columns are distinctly anticorrelated at high latitudes but are uncorrelated at low latitudes.

- Model simulations using the observed amount of $\mathrm{H}_{2} \mathrm{O}$ and the currently recommended kinetics underpredict $\mathrm{O}_{3}$ by about a factor of two. 


\begin{abstract}
Ozone $\left(\mathrm{O}_{3}\right)$ in the atmosphere of Mars is produced following the photolysis of $\mathrm{CO}_{2}$ and is readily destroyed by the hydrogen radicals $\left(\mathrm{HO}_{\mathrm{x}}\right)$ released by the photolysis and oxidation of water vapor. As a result, an anti-correlation between ozone and water vapor is expected. We describe here the $\mathrm{O}_{3}-\mathrm{H}_{2} \mathrm{O}$ relationship derived from four Martian years of simultaneous observations by the SPICAM spectrometer onboard the Mars Express spacecraft. A distinct anti-correlation is found at high latitudes, where the $\mathrm{O}_{3}$ column varies roughly with the -0.6 power of the $\mathrm{H}_{2} \mathrm{O}$ column. The $\mathrm{O}_{3}$ and $\mathrm{H}_{2} \mathrm{O}$ columns are uncorrelated at low latitudes. To evaluate our quantitative understanding of the Martian photochemistry, the observed $\mathrm{O}_{3}-\mathrm{H}_{2} \mathrm{O}$ relationship is then compared to that predicted by a global climate model with photochemistry. For identical model and observed abundances of $\mathrm{H}_{2} \mathrm{O}$, the model underpredicts observed ozone by about a factor of two relative to SPICAM when using the currently recommended gas-phase chemistry. Sensitivity studies employing low-temperature $\mathrm{CO}_{2}$ absorption cross-sections, or adjusted kinetics rates, do not solve this bias. Taking into account potential heterogeneous processes of $\mathrm{HO}_{\mathrm{x}}$ loss on clouds leads to a significant improvement, but only at high northern latitudes. More broadly, the modeled ozone deficits suggest that the $\mathrm{HO}_{\mathrm{x}}$-catalyzed photochemistry is too efficient in our simulations. This problem is consistent with the long-standing underestimation of CO in Mars photochemical models, and may be related to similar difficulties in modeling $\mathrm{O}_{3}$ and $\mathrm{HO}_{\mathrm{x}}$ in the Earth's upper stratosphere and mesosphere.
\end{abstract}

\title{
Plain language summary
}

The thin ozone layer on Mars is produced when the solar ultraviolet light breaks the $\mathrm{CO}_{2}$ molecules that compose $95 \%$ of its atmosphere. Conversely, ozone on Mars is readily destroyed by the hydrogen species released by water vapor. An inverse relationship is therefore expected between the quantities of ozone and water vapor. Quantifying this relationship provides important insight into the hydrogen chemistry that stabilizes the composition of the Mars atmosphere. We describe here the ozone and water vapor measurements performed during four Martian years (7.5 Earth years) by the SPICAM instrument onboard the Mars Express spacecraft. We then attempt to reproduce these measurements with a Mars climate model with photochemistry. Although the model reproduces the inverse relationship observed between ozone 
and water vapor, the ozone amount is underestimated by about a factor of two in the simulations. The ozone deficit suggests that the destruction by hydrogen species is too strong when one uses the currently recommended reaction rates. This problem is consistent with the long-standing underestimation in Mars models of carbon monoxide, also destroyed by hydrogen species, and can be related to similar difficulties in modeling ozone in the Earth's upper atmosphere.

\section{Introduction}

Ozone $\left(\mathrm{O}_{3}\right)$ in the atmosphere of Mars is a by-product of the photolysis of $\mathrm{CO}_{2}$ at ultraviolet wavelengths. It was discovered on Mars by the Mariner spectrometers (Barth and Hord, 1971; Barth et al., 1973), which detected $\mathrm{O}_{3}$ vertical columns of 10-50 $\mu \mathrm{m}$-atm that were only found in the polar regions. Compared to Earth, the very strong seasonal and spatial variability of the $\mathrm{O}_{3}$ column on Mars (a factor of $\sim 100$ as opposed to $\sim 3$ on our planet) is a striking feature of the Martian photochemistry. Ozone monitoring from the Earth (e.g., Clancy et al., 1999, Fast et al., 2006) and by satellite instruments (Perrier et al., 2006; Clancy et al., 2016; Willame et al., 2017) have shown that the $\mathrm{O}_{3}$ seasonal variability is largest at high latitudes, with a strong rise up to $\sim 50 \mu \mathrm{m}$-atm in winter-spring and ozone columns of $0-1 \mu \mathrm{m}$-atm at other seasons. At low latitudes, the same measurements show much less seasonal amplitude but give evidence of a broad maximum of about $3 \mu \mathrm{m}$-atm centered on Mars aphelion, followed by $\mathrm{O}_{3}$ columns of $\sim 1$ $\mu \mathrm{m}$-atm shortly after equinox.

Numerous modeling studies have demonstrated since the 1970s the crucial role played by water vapor in the chemistry and variations of ozone on Mars (Lefèvre and Krasnopolsky, 2017 and references therein). Water vapor is, as on Earth, the main source of ozone-destroying radicals $\mathrm{H}$, $\mathrm{OH}$, and $\mathrm{HO}_{2}$ (the $\mathrm{HO}_{x}$ family). $\mathrm{O}_{3}$ and $\mathrm{H}_{2} \mathrm{O}$ are therefore expected to be anti-correlated. This anti-correlation was demonstrated experimentally by Fast et al. (2006) from a limited dataset of $\mathrm{O}_{3}$ and $\mathrm{H}_{2} \mathrm{O}$ contemporaneous measurements, although not strictly coincident in space and time. The inverse relationship between $\mathrm{O}_{3}$ and $\mathrm{H}_{2} \mathrm{O}$ was also indirectly quantified through the emission of $\mathrm{O}_{2}\left({ }^{1} \Delta_{\mathrm{g}}\right)$, which is produced by $\mathrm{O}_{3}$ photolysis and was measured simultaneously with $\mathrm{H}_{2} \mathrm{O}$ by SPICAM (Guslyakova et al., 2016). 
In a larger sense, the tight coupling between $\mathrm{O}_{3}$ and $\mathrm{H}_{2} \mathrm{O}$ makes $\mathrm{O}_{3}$ a measurable tracer of the $\mathrm{HO}_{\mathrm{x}}$ chemistry that stabilizes the composition of the Mars $\mathrm{CO}_{2}$ atmosphere. The key role of $\mathrm{OH}$ in maintaining $95 \%$ of $\mathrm{CO}_{2}$ is indeed well established through the reaction

$$
\mathrm{CO}+\mathrm{OH} \rightarrow \mathrm{CO}_{2}+\mathrm{H}
$$

which recycles $\mathrm{CO}_{2}$ from its photolysis product $\mathrm{CO}$ (McElroy and Donahue, 1972; Parkinson and Hunten, 1972). However, the fact that all current models underestimate the amount of CO on Mars by a factor of 2 to 8 (Lefèvre and Krasnopolsky, 2017) suggests that a problem persists in our quantitative understanding of the $\mathrm{HO}_{\mathrm{x}}$ chemistry. For that reason, simultaneous measurements of $\mathrm{O}_{3}$ and $\mathrm{H}_{2} \mathrm{O}$ are a highly desirable constraint for chemical models, since any deviation between the theoretical and observed relationships between these two species is indicative of inaccurate or missing components in our description of the photochemistry.

This paper aims to characterize the relation observed between $\mathrm{O}_{3}$ and $\mathrm{H}_{2} \mathrm{O}$ on Mars, and to examine our ability to reproduce it with a state-of-the-art photochemical model. With its dual ultraviolet and infrared channels, the SPICAM spectrometer on board Mars Express is the first instrument that provided strictly simultaneous measurements of $\mathrm{O}_{3}$ (Perrier et al., 2006) and $\mathrm{H}_{2} \mathrm{O}$ (Trokhimovskiy et al., 2015). We exploit this dataset covering four martian years and tens of thousands of points to conduct at high and low latitudes a quantitative investigation of the relationship between the $\mathrm{O}_{3}$ and $\mathrm{H}_{2} \mathrm{O}$ columns on Mars. In a second step, we compare the observed $\mathrm{O}_{3}-\mathrm{H}_{2} \mathrm{O}$ anti-correlation curves to those calculated by the LMD global climate model. Sensitivity studies are carried out to examine the impact on the results of various hypotheses regarding the chemistry described in the model.

\section{SPICAM observations of Mars ozone and water vapor}

On board the Mars Express mission, the SPICAM instrument has been operating in orbit since December 2003. A detailed technical description of the instrument and each observation mode can be found in Bertaux et al. (2006), and a synthesis of the results obtained after 10 years of operation is presented by Montmessin et al. (2017). The dual ultraviolet-infrared channels of 
SPICAM allow studying the anti-correlation between $\mathrm{O}_{3}$ and $\mathrm{H}_{2} \mathrm{O}$ both in solar occultation or in nadir mode. The study of solar occultations is in theory more rigorous in the sense that the quantities of $\mathrm{O}_{3}$ and $\mathrm{H}_{2} \mathrm{O}$ are obtained at the same altitude and not integrated over the column. However, part of this advantage is lost by the fact that $\mathrm{O}_{3}$ varies greatly at sunrise and sunset, which complicates the analysis. The photochemical variation along the line of sight must be provided by a photochemical model (Piccialli et al., 2021), which may introduce in the measurement the model biases that we are trying to determine. This problem is avoided in nadir viewing if one excludes the measurements taken near solar terminators. Besides, the greater number of simultaneous measurements of the $\mathrm{O}_{3}$ and $\mathrm{H}_{2} \mathrm{O}$ columns compared to that of solar occultations (several tens of thousands vs. $\sim 600$ for SPICAM) provides more statistically significant results regarding the relationship between both species. Therefore, in this first quantitative investigation of the $\mathrm{O}_{3}-\mathrm{H}_{2} \mathrm{O}$ relationship, we will only discuss the observations in nadir mode. To be fair though, considering the vertically-integrated column inevitably skews our analysis towards the large pressures and hence the lower atmosphere. Our conclusions will be limited to altitudes typically below $30 \mathrm{~km}$ since variations in $\mathrm{O}_{3}$ or $\mathrm{H}_{2} \mathrm{O}$ at higher levels have little impact on the integrated column of these species.

\subsection{Ozone column}

In nadir viewing geometry, the ozone column is retrieved from the SPICAM ultraviolet (UV) channel between 210-290 $\mathrm{nm}$ simultaneously with the dust optical depth and surface albedo. Perrier et al. (2006) presented an initial version of the retrieval algorithm used to process the first 1.2 Martian year of SPICAM operation. In their method, a plane-parallel radiative transfer model was employed to fit the recorded spectra divided by a reference spectrum obtained at the top of Olympus Mons. The advantage of this "relative" method was to compensate for our incomplete knowledge of the instrument's calibration. More recently, Willame et al. (2017) developed their own version of the ozone column retrieval algorithm, by fitting directly the radiance factor $R_{f}$ defined as the ratio of the scattered light intensity (radiance) to the solar irradiance at the top of the atmosphere. In the present work, we use a largely rewritten version of the algorithm presented by Perrier et al. (2006), the main evolution being the adoption of a direct fitting of $R_{f}$ as in Willame et al. (2017). Indeed, thanks to a better characterization of the Point Spread 
Function (PSF) of the instrument and the so-called efficient area of the detector, as well as the improved modeling of stray light in nadir spectra (Montmessin et al., 2017), it is now possible to rely with good confidence on the absolute radiance returned by the UV channel. Hence, the algorithm no longer requires the use of a reference spectrum above Olympus Mons. This eliminates the risk of systematic error due to the unaccounted presence of dust or clouds in this spectrum. Other improvements in the method include the use of a radiative transfer model with a pseudo-spherical approximation (DISORT3, Lin et al., 2015), revised optical properties for aerosols (Wolff et al., 2010), and updated Rayleigh scattering cross-sections (Ityaksov et al., 2008). The solar fluxes used as references are monthly means of the ultraviolet irradiance measured by the SOLSTICE instrument on board the SORCE satellite (McClintock et al., 2005). The $\mathrm{O}_{3}$ column is retrieved simultaneously with the dust optical depth and the broadband ultraviolet albedo (210-290 nm), which includes the contribution of surface and clouds. Typical errors on the ozone column are of the order of $10 \%$ with a detection limit close to $0.5 \mu \mathrm{m}$-atm in dust-free conditions and in the absence of clouds. The error decreases to $5 \%$ for measurements performed above bright surface albedo as is the case in winter/spring in the polar regions. Larger errors $(30 \%)$ can occur in dusty conditions (Perrier et al., 2006), and $\mathrm{O}_{3}$ columns should be considered with great caution for dust opacities approaching 1. In the presence of clouds, the error on the $\mathrm{O}_{3}$ column results in an underestimation which may reach nearly $100 \%$ for a cloud opacity of 1 and low surface albedo. Thinner clouds with a UV opacity of $\sim 0.2$ over bright surface albedo lead to an average error of 15\%. Supporting information Figure S1 shows examples of radiance factors derived from SPICAM and corresponding retrieval fits obtained at the beginning of the mission (April 2004) over a wide range of latitudes, $\mathrm{O}_{3}$ columns, and albedo values.

As explained by Montmessin et al. (2017), SPICAM experienced a gradual deterioration of the UV channel characterized by sporadic and spurious changes of the high voltage setting during a sequence of observations. This behavior started in January 2006 but the data cleaning process could effectively identify the affected spectra and discard them until early 2012, when the worsening of the problem resulted in little usable data. The UV channel ceased eventually to return science data in December 2014. For reasons of precaution, we only consider here the measurements collected until September 2011, which allows us to cover four complete Martian 
years from the beginning of MY27 (orbit 205, 14 March 2004) to the end of MY30 (orbit 9812, 10 September 2011).

Figure 1 shows the zonally-averaged seasonal evolution of the ozone column retrieved by our algorithm from MY27 to MY30. Its characteristics are repeated from year to year and are similar in all respects to previous ozone climatologies obtained from SPICAM (Perrier et al., 2006; Willame et al., 2017) and MARCI (Clancy et al., 2016). The largest $\mathrm{O}_{3}$ columns are seen in the sunlit parts of the polar vortices. Due to Mars Express orbit and operational constraints from other instruments, the polar ozone maximum is better covered by SPICAM in the Northern Hemisphere, where the highest values occur for all Martian years in the short period $\mathrm{L}_{\mathrm{s}}=16-24^{\circ}$. In early spring, the $\mathrm{O}_{3}$ columns at high latitudes are known to show a strong day-to-day variability due to planetary wave activity (e.g., Lefèvre et al., 2004; Clancy et al., 2016). The annual maximum recorded by SPICAM during the Northern Hemisphere spring is comprised between $25 \mu \mathrm{m}$-atm for MY27 and $51 \mu \mathrm{m}$-atm for MY29, which appears to be in good quantitative agreement with the range of values observed by Clancy et al. (2016) and Willame et al. (2017). At low latitudes and in the summer hemisphere, the $\mathrm{O}_{3}$ columns are much lower and close to the detection limit of SPICAM, except near Mars aphelion $\left(\mathrm{L}_{\mathrm{s}}=71^{\circ}\right)$. Measurements in that season indicate a broad peak of 2-3 $\mu \mathrm{m}$-atm, in line with previous satellite observations (Perrier et al., 2006; Clancy et al., 2016). Around $\mathrm{L}_{\mathrm{s}}=240^{\circ}$, we also notice anomalously elevated ( $>5 \mu \mathrm{m}$-atm) $\mathrm{O}_{3}$ columns around at $30 \mathrm{~N}$ in MY28, and to a lesser extent at the Equator in MY29. As already experienced in previous UV measurements of Mars ozone (Clancy et al., 2016; Willame et al., 2017), these cases correspond to observations performed in high dust loading $(\tau>1)$. In those conditions of strongly reduced Rayleigh scattering, the retrieval is unable to distinguish correctly the scattering/absorption by dust, leading to false $\mathrm{O}_{3}$ detection. Such artifacts were particularly present during the global dust storm of MY28 $\left(\mathrm{L}_{\mathrm{s}}=270-300^{\circ}\right)$, but are discarded in Figure 1 when the retrieved dust optical depth $\tau$ is greater than 3 . 

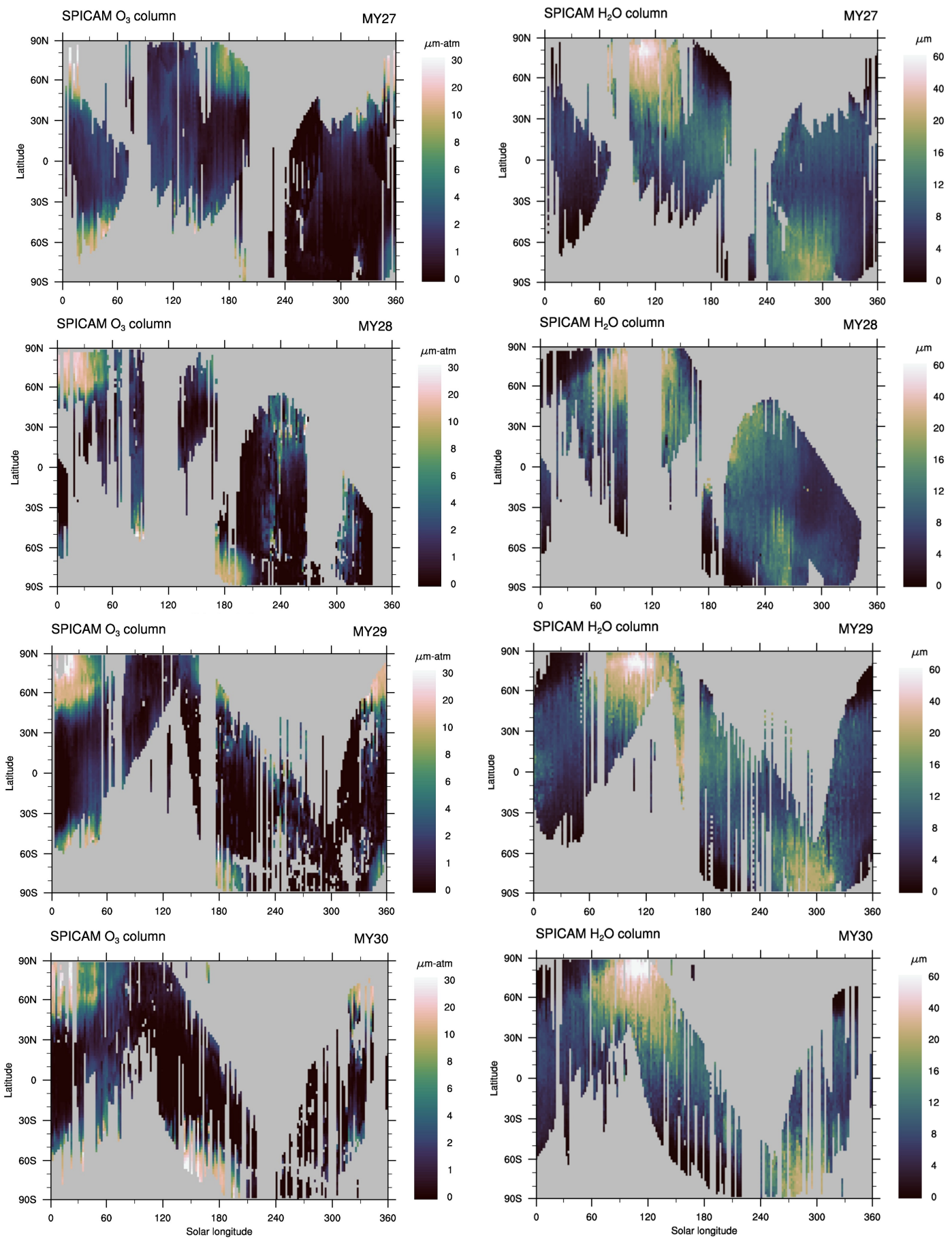

Figure 1. Overview of the SPICAM ozone (left) and water vapor (right) column abundance as a function of season, latitude, and Mars year. The columns are zonally averaged and binned by $2^{\circ}$ in $\mathrm{L}_{\mathrm{s}}$ and $2^{\circ}$ in latitude. Units are micron-atmosphere $(\mu \mathrm{m}$-atm) for ozone and precipitable micron (pr- $\mu \mathrm{m})$ for water vapor. 


\subsection{Water vapor column}

The water vapor column is retrieved from the near-infrared channel of SPICAM using nadir observations of the $1.38 \mu \mathrm{m} \mathrm{H}_{2} \mathrm{O}$ band. This channel is composed of a light $(0.8 \mathrm{~kg})$ spectrometer that uses the principle of the acousto-optic filtering of light (AOTF) in the wavelength range 1.0-1.7 $\mu \mathrm{m}$. A detailed technical description of the instrument, which is still operating flawlessly at the time of writing, can be found in Korablev et al. (2006). We limit ourselves here to the data collected between the beginning of MY27 and the end of MY30, when reliable UV data are available at the same time.

The SPICAM $\mathrm{H}_{2} \mathrm{O}$ columns have been retrieved with the algorithm described in detail by Trokhimovskiy et al. (2015). Compared to the initial version of the retrieval method reported in Fedorova et al. (2006), the processing includes several improvements including in particular a better characterization of the instrument calibration, new solar spectrum, and accounting for multiple scattering by dust and water ice clouds. The total uncertainty on the water vapor column averaged on a $2^{\circ}$ latitude bin is estimated not to exceed $6 \%$ in low dust conditions (Trokhimovskiy et al., 2015).

Figure 1 shows the zonally-averaged gridded $\mathrm{H}_{2} \mathrm{O}$ dataset in regard to the $\mathrm{O}_{3}$ dataset from $\mathrm{MY} 27$ to MY30. The seasonal evolution of the $\mathrm{H}_{2} \mathrm{O}$ column as seen by SPICAM has already been extensively discussed by Trokhimovskiy et al. (2015) and is to a large extent in good agreement with previous multi-annual monitoring of $\mathrm{H}_{2} \mathrm{O}$ (Smith et al., 2004). At first order, Figure 1 shows the obvious anti-correlation that exists between the large-scale seasonal evolution of ozone and water vapor. This is particularly visible at high latitudes, where the $\mathrm{O}_{3}$ maxima coincide with the low $\mathrm{H}_{2} \mathrm{O}$ columns measured in winter-spring, whereas $\mathrm{O}_{3}$ is much reduced during the summer peaks of $\mathrm{H}_{2} \mathrm{O}$. Beyond this first expected finding, the data coverage in Figure 1 illustrates the unprecedented opportunity offered by SPICAM to conduct a quantitative analysis of the anti-correlation between $\mathrm{O}_{3}$ and $\mathrm{H}_{2} \mathrm{O}$ based on several thousands of measurements made at exactly the same time and location, at all latitudes and seasons.

\section{Three-dimensional simulations}


3.1 Updated version of the LMD global climate model with photochemistry

To interpret the SPICAM data we use the latest version of the LMD global climate model (GCM) with coupled photochemistry (Forget et al., 1999; Lefèvre et al., 2004). In recent years the model has received a number of improvements that concern both the description of physics and that of photochemistry. Regarding physics, the GCM includes a "semi-interactive" dust transport scheme coupled to the radiative transfer calculations (Madeleine et al., 2011), and takes into account the radiative effect of water ice clouds (Madeleine et al., 2012). These two developments significantly improve the GCM temperature predictions over the Martian year. For a better representation of the planetary boundary layer, the convection and near-surface turbulence are parameterized using a thermal plume model, validated against lander measurements (Colaitis et al., 2013). We also use here the extension of the GCM to the thermosphere (Angelats I Coll et al., 2005; González-Galindo et al., 2009), which contains the improved parameterization of the $\mathrm{CO}_{2}$ $15 \mu \mathrm{m}$ cooling described in González-Galindo et al. (2013). The top of the model therefore corresponds to roughly $200-300 \mathrm{~km}$, depending on the thermal structure.

On Mars, the description of the water cycle is of crucial importance for faithful reproduction of photochemistry and ozone. The LMD GCM adopts the new implementation of the water cycle described by Navarro et al. (2014). In this scheme, a detailed cloud microphysics inherited from Montmessin et al. (2002) takes into account nucleation on dust particles, ice particle growth, and scavenging of dust particles due to the condensation of ice. With these methods, water vapor supersaturation is predicted above the hygropause as observed by SPICAM (Maltagliati et al., 2011) although indirect measurements by the CRISM instrument suggest that the modeled $\mathrm{H}_{2} \mathrm{O}$ is overestimated in the middle atmosphere (Clancy et al., 2017). Finally, the water cycle was recently improved by a decrease in the physical timestep and an increase of the GCM vertical resolution, leading to less opaque polar hoods in better agreement with the observations (Vals et al., 2018).

Concerning photochemistry, the scheme implemented in the GCM has been profoundly reworked by merging the lower atmosphere code of Lefèvre et al. (2004) and the thermospheric code of 
González-Galindo et al. $(2005,2013)$. The model thus provides a unified description of the photochemistry of $\mathrm{CO}_{2}$, oxygen, hydrogen, and nitrogen from the surface to the exobase. To solve the ordinary differential equation systems associated with the time evolution of the species concentrations, we have adopted the adaptive semi-implicit scheme (ASIS) developed by Cariolle et al. (2017). This solver conserves mass and does not require any a priori hypothesis on the lifetime of chemical species. Finally, another improvement concerns the calculation of photolysis rates, carried out on-line over the whole altitude range. This is similar to what was done in the thermospheric model of González-Galindo et al. (2005), but we use here an increased spectral resolution (162 vs. 36 spectral bins) to better resolve the fine structures of the $\mathrm{CO}_{2}$ cross-sections that are important in the lower atmosphere. The ultraviolet radiative transfer model, adapted from the terrestrial TUV model (Madronich and Flocke, 1998), takes into account the absorption and scattering by airborne dust. The calculation of photodissociation rates is therefore fully interactive with the dust profile predicted for each grid point by the GCM.

The chemical scheme considers the neutral species $\mathrm{CO}_{2}, \mathrm{CO}, \mathrm{O}\left({ }^{3} \mathrm{P}\right), \mathrm{O}\left({ }^{1} \mathrm{D}\right), \mathrm{O}_{2}, \mathrm{O}_{3}, \mathrm{H}, \mathrm{H}_{2}, \mathrm{OH}$, $\mathrm{HO}_{2}, \mathrm{H}_{2} \mathrm{O}_{2}, \mathrm{H}_{2} \mathrm{O}, \mathrm{N}, \mathrm{N}\left({ }^{2} \mathrm{D}\right), \mathrm{NO}, \mathrm{NO}_{2}, \mathrm{~N}_{2}$, and Ar. The list of reactions and photolytic processes that link these species in the GCM can be found in Lefèvre et al. (2004) and González-Galindo et al. (2013). In its nominal configuration, the GCM only considers gas-phase processes. Most of the reaction rates, branching ratios, and absorption cross-sections are those recommended by the latest Jet Propulsion Laboratory compilation (Burkholder et al., 2015) widely used in the Earth stratospheric community. The greater efficiency of $\mathrm{CO}_{2}$ as a third body is taken into account for all three-body reactions. We adopt in particular the absolute $\mathrm{O}_{3}$ formation rate determined in a $\mathrm{CO}_{2}$ bath at room temperature by Sehested et al. (1995), and the temperature dependence recommended by Burkholder et al. (2015). Regarding the $\mathrm{CO}_{2}$ absorption cross-sections, we use a composite dataset built from the measurements of Huestis and Berkowitz (2010) between 0.1-106 nm, Stark et al. (2007) at $195 \mathrm{~K}$ between 106-118 nm, Yoshino et al. (1996) at $195 \mathrm{~K}$ between 118-163 nm, and Parkinson et al. (2003) at $195 \mathrm{~K}$ and $295 \mathrm{~K}$ between 163 and $200 \mathrm{~nm}$. $\mathrm{CO}_{2}$ cross-sections are extrapolated down to $210 \mathrm{~nm}$ after subtraction of Rayleigh scattering. For $\mathrm{H}_{2} \mathrm{O}$, the absorption cross-sections are taken from Mota et al. (2005) between 114-140 nm, and from the data measured at $250 \mathrm{~K}$ by Chung et al. (2001) between 140-190 nm, also extrapolated to $200 \mathrm{~nm}$. Another notable exception specific to Mars is the condensation of $\mathrm{H}_{2} \mathrm{O}_{2}$, which is 
removed from the atmosphere in the model when its vapor pressure reaches saturation (Lindner et al., 1988).

For all our simulations, the GCM was integrated with a horizontal resolution of 5.6 longitude $\times$ $3.75^{\circ}$ latitude. The vertical discretization comprises 73 levels, leading to a resolution of about 1 $\mathrm{km}$ at $10 \mathrm{~km}, 2 \mathrm{~km}$ at $30 \mathrm{~km}, 3 \mathrm{~km}$ at $50 \mathrm{~km}$, and $5 \mathrm{~km}$ at $70 \mathrm{~km}$. The GCM was initialized from the results at $\mathrm{L}_{\mathrm{s}}=180^{\circ}$ of a multiannual simulation. At that date, $\mathrm{Ar}, \mathrm{N}_{2}$, and $\mathrm{O}_{2}$ were reset according to the values measured by the Mars Science Laboratory (Trainer et al., 2019). CO was scaled to reach 1000 ppmv in the lower atmosphere (Smith et al., 2018; Olsen et al., 2020a) and $\mathrm{H}_{2}$ was set to 15 ppmv (Krasnopolsky and Feldman, 2001). The results discussed here were obtained in the second year of simulation.

\subsection{GCM ozone and water vapor climatologies compared to SPICAM}

Figure 2 compares the climatologies of $\mathrm{O}_{3}$ and $\mathrm{H}_{2} \mathrm{O}$ calculated by the nominal simulation of the LMD GCM to the SPICAM observations averaged over Martian years 27 to 30. For convenience, the GCM results are plotted at 1200 LT but the variations with local time are taken into account in the rest of this study. The overall agreement already noted by Navarro et al. (2014) between the GCM water cycle and the observations by the Thermal Emission Spectrometer (TES) is repeated with the $\mathrm{H}_{2} \mathrm{O}$ columns measured by SPICAM. Compared to the results of Navarro et al. (2014), the improvements proposed by Vals et al. (2018) lead to a less pronounced southern summer maximum that is more in agreement with observations, although it occurs slightly too early in the season. The main quantitative difference between the model and SPICAM concerns the Northern Hemisphere maximum in summer, which is overpredicted and extends too far towards low latitudes, where a wet bias is evident.

Regarding the ozone column, the $\mathrm{L}_{\mathrm{s}}$-latitude climatology calculated by the GCM displays a temporal and seasonal distribution that is dominated by the winter polar maximums and is in broad agreement with SPICAM data. Substantial quantitative differences are however apparent. In particular, the model consistently underpredicts the ozone column measured in the sunlit parts 
of both polar vortices. At low latitudes, the aphelion maximum well identified in the SPICAM climatology is also present but barely visible in the simulation.

These results indicate that the general underestimation of ozone by the LMD GCM noted by Clancy et al. (2016) persists in the current nominal configuration of the model. Before invoking a misrepresentation of the photochemistry, it is essential to check whether a bias in water vapor modeling can explain the underestimation of the amount of ozone. This type of work has been undertaken by Holmes et al. (2018), who could relate some disagreements between observed and modeled ozone to wet water vapor biases in the UK version of the LMD GCM. This illustrates the difficulty of disentangling the effects of photochemistry from those due to incorrect amounts of water vapor, which are inevitably described in an imperfect way in the models. Rather than trying to obtain a water vapor field that precisely matches in time and space the observations, an easier way to isolate potential issues in modeled photochemistry is to address the question: how much ozone is calculated for a given amount of water vapor? The reply does not require perfect modeling of the water cycle, and can be directly compared to observations, provided that simultaneous measurements of $\mathrm{O}_{3}$ and $\mathrm{H}_{2} \mathrm{O}$ are available. This exercise is carried out here for all the latitudes and seasons sampled by the SPICAM data, which are discussed in the next section. 



Figure 2. Climatologies of SPICAM ozone and water vapor as a function of $\mathrm{L}_{\mathrm{s}}$ and latitude, compared to the LMD GCM nominal simulation. Left: SPICAM $\mathrm{O}_{3}$ (top) and $\mathrm{H}_{2} \mathrm{O}$ (bottom) column, averaged over Mars years 27 to 30 . The columns are zonally averaged and binned by $2^{\circ}$ in $\mathrm{L}_{\mathrm{s}}$ and $2^{\circ}$ in latitude. Right: LMD GCM nominal simulation of $\mathrm{O}_{3}$ (top) and $\mathrm{H}_{2} \mathrm{O}$ (bottom) calculated at 1200 local time. Units are $\mu \mathrm{m}$-atm for ozone and $\mathrm{pr}-\mu \mathrm{m}$ for water vapor.

\section{The $\mathrm{O}_{3}-\mathrm{H}_{2} \mathrm{O}$ relationship as seen by SPICAM}

Measurements of the vertically-integrated column of a given constituent are mostly sensitive to the amounts present in the first scale heights of the atmosphere, owing to the larger pressure. Ideally, the characterization of the anti-correlation between $\mathrm{O}_{3}$ and $\mathrm{H}_{2} \mathrm{O}$ from their columns 
should therefore be conducted when both species present maximum number densities in the lower atmosphere. On Mars, this condition is in general only valid at high latitudes. Observations of the $\mathrm{O}_{3}$ profile performed at twilight (Gröller et al., 2018; Piccialli et al., 2021; Olsen et al., 2020b) or during the night (Lebonnois et al., 2006; Montmessin and Lefèvre, 2013) show that the $\mathrm{O}_{3}$ polar layer in both hemispheres is, in terms of number density, essentially confined below 30 $\mathrm{km}$. Regarding $\mathrm{H}_{2} \mathrm{O}$, vertical excursions are greatly restricted by the altitude of saturation. In the polar regions, the $\mathrm{H}_{2} \mathrm{O}$ vertical profile expressed in number density (Fedorova et al., 2021) shows a distribution also generally limited to altitudes below $30 \mathrm{~km}$, except around perihelion (Ls = $240^{\circ}-270^{\circ}$ ) when substantial $\mathrm{H}_{2} \mathrm{O}$ densities can be observed up to $50 \mathrm{~km}$. Outside this period, the vertical extent of $\mathrm{O}_{3}$ and $\mathrm{H}_{2} \mathrm{O}$ is therefore comparable. Polar regions also have the advantage of showing the greatest seasonal variations in $\mathrm{O}_{3}$ and $\mathrm{H}_{2} \mathrm{O}$, enabling examination of the $\mathrm{O}_{3}-\mathrm{H}_{2} \mathrm{O}$ relation over the largest amplitude of values. For these reasons, this work will mainly focus on high latitudes of both hemispheres $\left(60^{\circ} \mathrm{N}-90^{\circ} \mathrm{N}\right.$ and $\left.60^{\circ} \mathrm{S}-90^{\circ} \mathrm{S}\right)$. The situation is more complicated at mid-to-low latitudes, where the main change in $\mathrm{O}_{3}$ occurs around aphelion when a layer of $\mathrm{O}_{3}$ forms in the middle atmosphere $(\sim 40 \mathrm{~km})$ above the bulk of the $\mathrm{H}_{2} \mathrm{O}$ layer (Clancy and Nair, 1996; Lebonnois et al., 2006; Gröller et al., 2018). This makes the search for a causal relationship between $\mathrm{O}_{3}$ and $\mathrm{H}_{2} \mathrm{O}$ less relevant when only considering the vertically-integrated columns. Nevertheless, results obtained at low latitudes $\left(15^{\circ} \mathrm{N}-15^{\circ} \mathrm{S}\right)$ will be shown to illustrate the limitations of the method and for comparison with models.

We present the results in the form of correlation plots of $\mathrm{O}_{3}$ versus $\mathrm{H}_{2} \mathrm{O}$ using a $2^{\circ} \times 2^{\circ} \times 2^{\circ}$ latitude-longitude- $\mathrm{L}_{s}$ grid constructed for both species. The analysis eliminates the data for which the dust optical depth $\tau$ retrieved in the UV channel is greater than 0.8 . This condition severely reduces the number of observations retained during the perihelion season but ensures that the false $\mathrm{O}_{3}$ detections sometimes returned by the algorithm in conditions of high dust opacity are properly eliminated. We also exclude measurements close to terminators (solar zenith angle > $75^{\circ}$ ), where $\mathrm{O}_{3}$ may exhibit rapid photochemical variations uncorrelated to $\mathrm{H}_{2} \mathrm{O}$. Finally, the $\mathrm{O}_{3}$ retrievals with poor fits $\left(X^{2}>3\right.$, representing $3 \%$ of the data) are discarded from the analysis.

\subsection{High northern latitudes $\left(60^{\circ} \mathrm{N}-90^{\circ} \mathrm{N}\right)$}


In the $60^{\circ} \mathrm{N}-90^{\circ} \mathrm{N}$ latitude band (Figure 3a), the distribution of the SPICAM data taken as a whole shows an obvious anti-correlation between the $\mathrm{O}_{3}$ and $\mathrm{H}_{2} \mathrm{O}$ columns. Between 0.5 and 50 pr- $\mu$ m of $\mathrm{H}_{2} \mathrm{O}, \mathrm{O}_{3}$ is roughly proportional to $\left(\mathrm{H}_{2} \mathrm{O}\right)^{-0.6}$. The top of the $\mathrm{O}_{3}-\mathrm{H}_{2} \mathrm{O}$ curve shows a plateau with considerable scattering of the data points. Part of this dispersion can be attributed to the uncertainty on the $\mathrm{H}_{2} \mathrm{O}$ column, which becomes substantial for amounts lower than $1 \mathrm{pr}-\mu \mathrm{m}$. In those dehydrated conditions, the absence of tight anti-correlation between $\mathrm{O}_{3}$ and $\mathrm{H}_{2} \mathrm{O}$ can also be understood from the results of the LMD GCM extracted at $65^{\circ} \mathrm{N}$ (Figure 4). It can be seen that the $\mathrm{O}_{3}$ polar layer is essentially confined in the first $5 \mathrm{~km}$ above the surface. In this altitude range, the model calculates that for a $\mathrm{H}_{2} \mathrm{O}$ column of $0.3 \mathrm{pr}-\mu \mathrm{m}$, about $80 \%$ of the $\mathrm{HO}_{\mathrm{x}}$ production comes from the reaction

$$
\mathrm{H}_{2}+\mathrm{O}\left({ }^{1} \mathrm{D}\right) \rightarrow \mathrm{OH}+\mathrm{H}
$$

and not from the photolysis or oxidation of $\mathrm{H}_{2} \mathrm{O}$. This result agrees with previous modeling studies (Lindner, 1988; Lefèvre et al., 2004). Therefore, in the northern polar vortex $\mathrm{H}_{2} \mathrm{O}$ is no longer the main supplier of ozone-destroying $\mathrm{HO}_{\mathrm{x}}$ radicals. Instead of this, $\mathrm{O}\left({ }^{1} \mathrm{D}\right)$ in reaction (2) being primarily formed by $\mathrm{O}_{3}$ photolysis, $\mathrm{O}_{3}$ regulates its own destruction. However, the amount of $\mathrm{HO}_{x}$ produced by reaction (2) is small, such that the chemical lifetime for $\mathrm{O}_{3}$ can reach several days close to the surface. This makes the $\mathrm{O}_{3}$ column predominantly controlled by dynamical processes at all spatio-temporal scales within the polar vortex, which are probably a major cause for the dispersion in the data in Figure 3a. A minor role is played by the photochemical variation of the $\mathrm{O}_{3}$ column with local time, which is of the order of $10 \%$ at polar latitudes (Holmes et al., 2018).

Careful examination of Figure $3 \mathrm{a}$ also indicates that for $\mathrm{H}_{2} \mathrm{O}$ columns smaller than $1 \mathrm{pr}-\mu \mathrm{m}$, the $\mathrm{O}_{3}$ column is substantially larger in spring $\left(\mathrm{L}_{\mathrm{s}}=0^{\circ}-30^{\circ}\right)$ than in autumn $\left(\mathrm{L}_{\mathrm{s}}=150^{\circ}-180^{\circ}\right)$, despite identical conditions of solar radiation. This asymmetry in the $\mathrm{O}_{3}-\mathrm{H}_{2} \mathrm{O}$ relation is also visible in the GCM climatology in Figure 2, which shows significantly larger polar $\mathrm{O}_{3}$ columns in spring than in autumn. 
The intermediate $\mathrm{H}_{2} \mathrm{O}$ values between 1 and $10 \mathrm{pr}-\mu \mathrm{m}$ are typical of the outer edge of the polar vortex. Between $\mathrm{L}_{\mathrm{s}}=30^{\circ}-60^{\circ}$, SPICAM data indicate that the $\mathrm{O}_{3}$ chemical lifetime can be sufficiently long to maintain the occasional occurrence of high $\mathrm{O}_{3}$ columns $(\sim 10 \mu \mathrm{m}$-atm) despite $\mathrm{H}_{2} \mathrm{O}$ columns of several pr- $\mu \mathrm{m}$. This phenomenon is not observed in the GCM nominal simulation (Figure 2) and creates a shoulder in the averaged $\mathrm{O}_{3}-\mathrm{H}_{2} \mathrm{O}$ relation. In contrast, despite comparable conditions of solar light, the observations performed in late summer $\left(\mathrm{L}_{\mathrm{s}}=\right.$ $150^{\circ}-180^{\circ}$ ) show lower $\mathrm{O}_{3}$ values and a tighter $\mathrm{O}_{3}-\mathrm{H}_{2} \mathrm{O}$ anti-correlation. This difference also contributes to the asymmetry noted between the spring and autumn $\mathrm{O}_{3}$ abundance.

Finally, for $\mathrm{H}_{2} \mathrm{O}$ columns larger than $10 \mathrm{pr}-\mu \mathrm{m}$, the anti-correlation between $\mathrm{O}_{3}$ and $\mathrm{H}_{2} \mathrm{O}$ is still visible. On average, the slope of the inverse relationship is similar to that found in dryer environments, if one disregards the shoulder mentioned above at $\mathrm{L}_{\mathrm{s}}=30^{\circ}-60^{\circ}$. In summer, when the $\mathrm{H}_{2} \mathrm{O}$ columns measured by SPICAM approach their annual maximum, the average $\mathrm{O}_{3}$ column is about $1 \mu \mathrm{m}$-atm and occasionally reaches $3 \mu \mathrm{m}$-atm. $\mathrm{O}_{3}$ is therefore always present in measurable quantities in the north polar regions, even in the intuitively unfavorable conditions of the north polar cap sublimation season. This phenomenon is also visible in the MARCI data, showing $\mathrm{O}_{3}$ columns around $1 \mu \mathrm{m}$-atm near the North Pole in summer (Daerden et al., 2019).

\subsection{High southern latitudes $\left(60^{\circ} \mathrm{S}-90^{\circ} \mathrm{S}\right)$}

Due to UV dust opacities often exceeding the criterion $\tau<0.8$ in summer and spring, the high southern latitudes are less well sampled than in the Northern Hemisphere. Nevertheless, the anti-correlation between $\mathrm{O}_{3}$ and $\mathrm{H}_{2} \mathrm{O}$ is clearly visible (Figure 3b). The $\mathrm{O}_{3}-\mathrm{H}_{2} \mathrm{O}$ relation follows approximately the same slope as in the Northern Hemisphere, but is shifted downwards: in the Southern Hemisphere the $\mathrm{O}_{3}$ column is lower by a factor of $\sim 3$ for a $\mathrm{H}_{2} \mathrm{O}$ column of $1 \mathrm{pr}-\mu \mathrm{m}$, and by a factor of $\sim 10$ for $5 \mathrm{pr}-\mu \mathrm{m}$. For $\mathrm{H}_{2} \mathrm{O}$ columns above $5 \mathrm{pr}-\mu \mathrm{m}, 95 \%$ of the retrieved $\mathrm{O}_{3}$ values are below the detection limit of $0.5 \mu \mathrm{m}$-atm. This stark north-south asymmetry results from the difference in surface elevation, which at high latitudes is on average $6 \mathrm{~km}$ higher in the Southern Hemisphere than in the Northern Hemisphere. In Figure 4, the LMD GCM results extracted at $65^{\circ} \mathrm{S}$ show that the lower pressure and hence lower UV opacity of $\mathrm{CO}_{2}$ translates to a $\mathrm{H}_{2} \mathrm{O}$ photolysis increased near the surface by a factor of 3 , which now dominates the $\mathrm{HO}_{\mathrm{x}}$ production 
from $3 \mathrm{~km}$ upwards. Second, the three-body production path for $\mathrm{O}_{3}$ is less efficient at lower pressure. This shifts the equilibrium within the $\mathrm{O}_{\mathrm{x}}$ family $\left(\mathrm{O}_{\mathrm{x}}=\mathrm{O}+\mathrm{O}_{3}\right)$ towards $\mathrm{O}$, making more atomic oxygen available for the main $\mathrm{O}_{\mathrm{x}}$ loss reaction:

$$
\mathrm{HO}_{2}+\mathrm{O} \rightarrow \mathrm{H}+\mathrm{O}_{2}
$$

Both effects explain why for the same $\mathrm{H}_{2} \mathrm{O}$ amount, the $\mathrm{O}_{3}$ destruction by $\mathrm{HO}_{\mathrm{x}}$ is more efficient and $\mathrm{O}_{3}$ is less abundant in the elevated southern polar latitudes than in the low plains of the Northern Hemisphere (Figure 4). The fact that the $\mathrm{H}_{2} \mathrm{O}$ photolysis accounts for a significant part of the $\mathrm{HO}_{x}$ production may also explain why the $\mathrm{O}_{3}-\mathrm{H}_{2} \mathrm{O}$ relation in Figure $3 \mathrm{~b}$ does not show the flattening that is visible in the Northern Hemisphere for $\mathrm{H}_{2} \mathrm{O}$ values below $0.5 \mathrm{pr}-\mu \mathrm{m}$.

\subsection{Low latitudes $\left(15^{\circ} \mathrm{N}-15^{\circ} \mathrm{S}\right)$}

Figure $3 \mathrm{c}$ displays the $\mathrm{O}_{3}-\mathrm{H}_{2} \mathrm{O}$ relation found from SPICAM between $15^{\circ} \mathrm{N}-15^{\circ} \mathrm{S}$. The maximum $\mathrm{O}_{3}$ columns measured in the aphelion season $\left(\mathrm{L}_{\mathrm{s}}=0-90^{\circ}\right)$ are clearly not observed for the lowest $\mathrm{H}_{2} \mathrm{O}$ columns, and $\mathrm{O}_{3}$ shows in general a poor anti-correlation with $\mathrm{H}_{2} \mathrm{O}$. This confirms the theoretical result obtained with an early version of our GCM (Lefèvre et al., 2004) and measurements of the $\mathrm{O}_{2}\left({ }^{1} \Delta_{\mathrm{g}}\right)$ emission (Guslyakova et al., 2016), indicating that at low latitudes the $\mathrm{H}_{2} \mathrm{O}$ column is not a good predictor of the $\mathrm{O}_{3}$ column. Indeed, in those regions changes in $\mathrm{O}_{3}$ are essentially driven by the orbital $\left(\mathrm{L}_{\mathrm{s}}\right)$ variation in the $\mathrm{H}_{2} \mathrm{O}$ vertical distribution, which favors around aphelion the build-up of large $\mathrm{O}_{3}$ number densities in the middle atmosphere (Clancy and Nair, 1996). At those altitudes (i.e., low pressure), the changes in the small $\mathrm{H}_{2} \mathrm{O}$ number densities have a negligible impact on the $\mathrm{H}_{2} \mathrm{O}$ integrated column, explaining the absence of anti-correlation. In addition, unlike the $\mathrm{O}_{3}$ layer present near the surface, models suggest that the high-altitude $\mathrm{O}_{3}$ layer in the aphelion season varies substantially with local time during the day (e.g., Lefèvre et al., 2004; Picciali et al., 2021). This effect is uncorrelated with $\mathrm{H}_{2} \mathrm{O}$ and may also contribute to the scattering of the $\mathrm{O}_{3}$ data. 


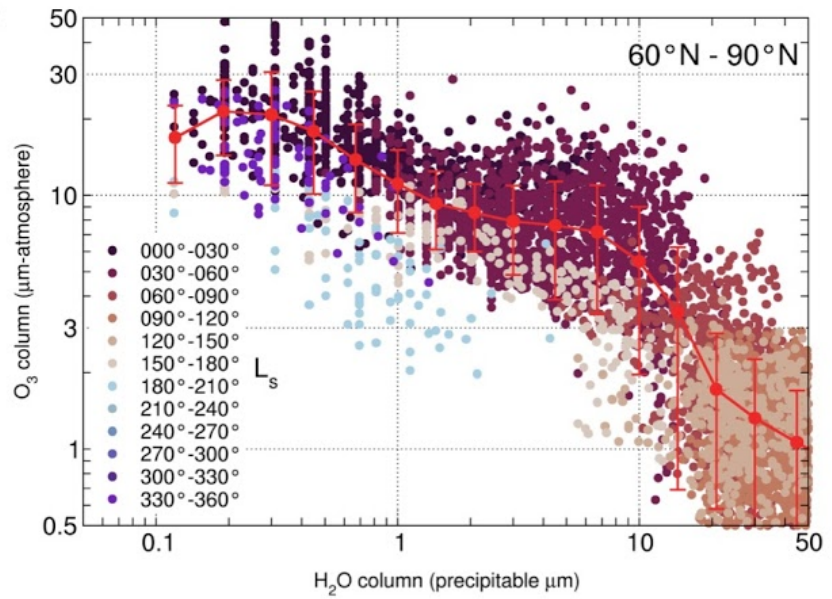

b

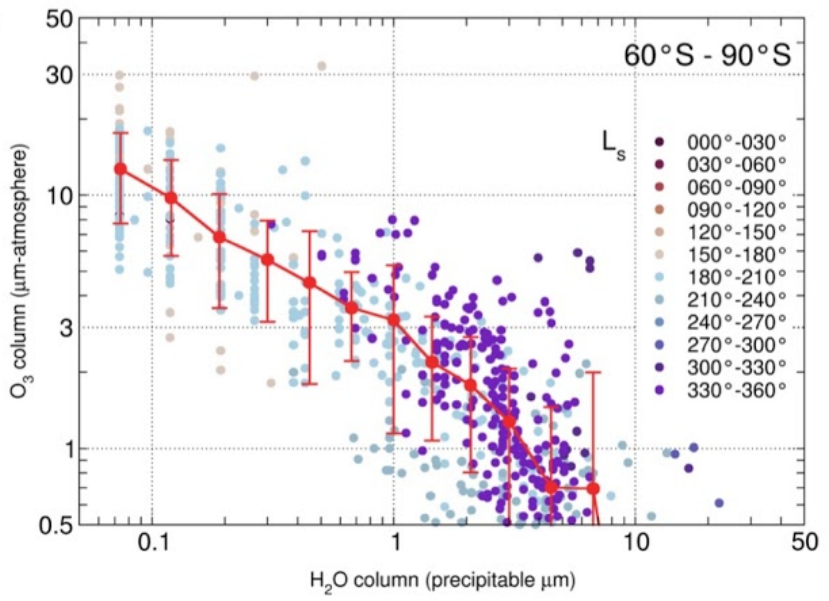

C

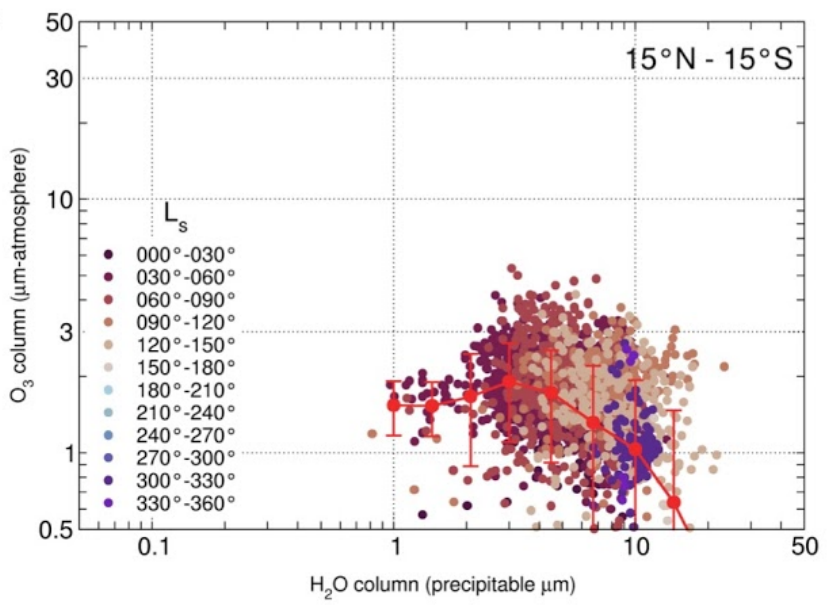

Figure 3. $\mathrm{O}_{3}$ column $(\mu \mathrm{m}-\mathrm{atm})$ vs. $\mathrm{H}_{2} \mathrm{O}$ column $(\mathrm{pr}-\mu \mathrm{m})$ measured simultaneously by SPICAM. (a) $60^{\circ} \mathrm{N}-90^{\circ} \mathrm{N}$. (b) $60^{\circ} \mathrm{S}-90^{\circ} \mathrm{S}$. (c) $15^{\circ} \mathrm{N}-15^{\circ} \mathrm{S}$. Colors indicate the $\mathrm{L}_{\mathrm{s}}$ interval. Red circles and error bars represent the mean and $1-\sigma$ standard deviation of the distribution. 

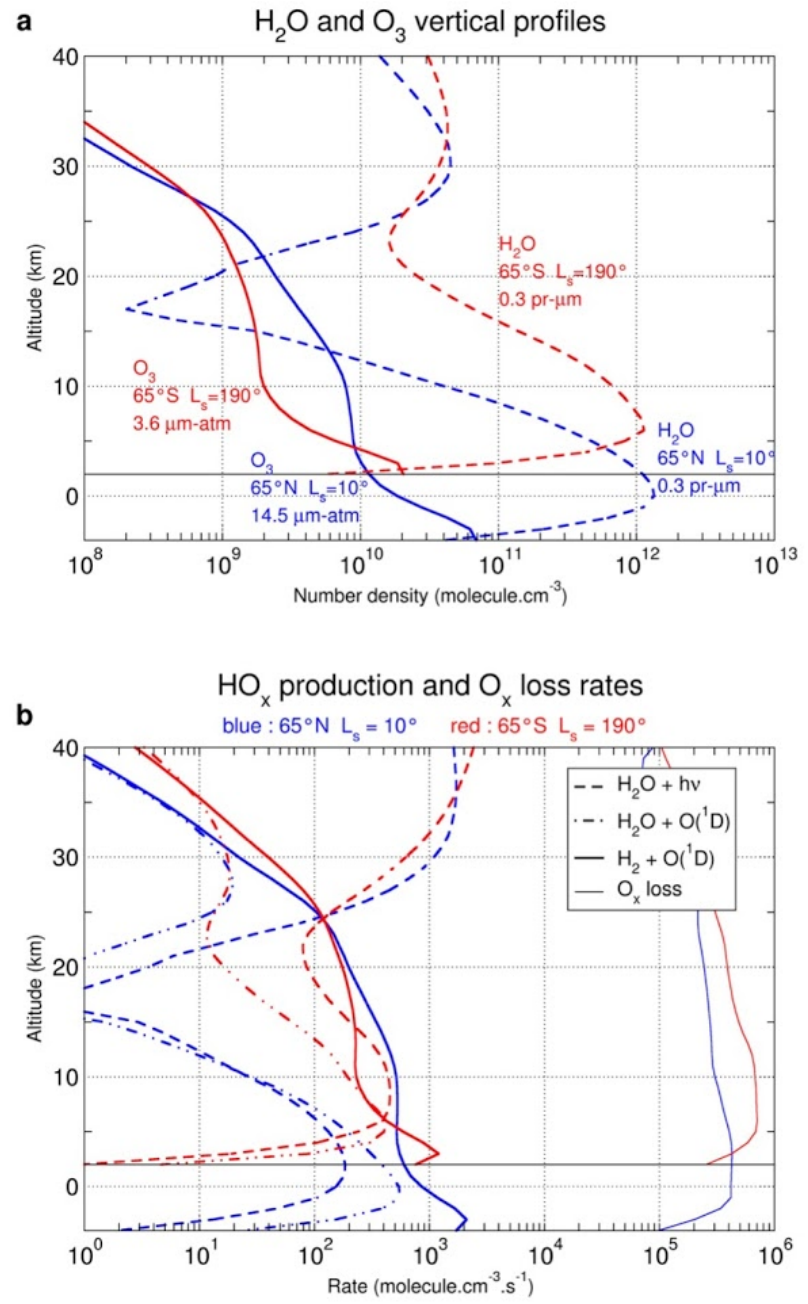

Figure 4. Examples of profiles of $\mathrm{O}_{3}, \mathrm{H}_{2} \mathrm{O}$, and production/loss rates calculated by the LMD GCM at high latitudes in early spring. Altitude is relative to the Mars areoid and local time is 1200. (a) $\mathrm{O}_{3}$ and $\mathrm{H}_{2} \mathrm{O}$ number densities at $65^{\circ} \mathrm{N}\left(\mathrm{L}_{\mathrm{s}}=10^{\circ}\right)$ and $65^{\circ} \mathrm{S}\left(\mathrm{L}_{\mathrm{s}}=190^{\circ}\right)$. (b) $\mathrm{HO}_{\mathrm{x}}$ production rate for the most important reactions and $\mathrm{O}_{\mathrm{x}}$ loss rate at $65^{\circ} \mathrm{N}\left(\mathrm{L}_{\mathrm{s}}=10^{\circ}\right)$ and $65^{\circ} \mathrm{S}\left(\mathrm{L}_{\mathrm{s}}\right.$ $\left.=190^{\circ}\right)$. 


\section{Simulating the $\mathrm{O}_{3}-\mathrm{H}_{2} \mathrm{O}$ relation}

We now assess the ability of the LMD GCM to reproduce the $\mathrm{O}_{3}-\mathrm{H}_{2} \mathrm{O}$ relation as determined by SPICAM. For each of the latitude bands discussed above, the $\mathrm{O}_{3}$ and $\mathrm{H}_{2} \mathrm{O}$ columns calculated by the model were extracted at the same location, season, and local time as the individual SPICAM measurements. The impact of topography, as well as $\mathrm{O}_{3}$ photochemical variations with solar zenith angle, are therefore taken into account. The GCM was first integrated in its nominal configuration and then with modified settings to explore the sensitivity of the results.

\subsection{Nominal simulation}

Figure 5a plots the $\mathrm{O}_{3}-\mathrm{H}_{2} \mathrm{O}$ relation obtained with the nominal simulation in the $60^{\circ} \mathrm{N}-90^{\circ} \mathrm{N}$ latitude band. As for SPICAM, the modeled $\mathrm{O}_{3}$ shows a clear anti-correlation with $\mathrm{H}_{2} \mathrm{O}$. However, except for the largest $\mathrm{H}_{2} \mathrm{O}$ columns measured in summer $\left(\mathrm{H}_{2} \mathrm{O}>20 \mathrm{pr}-\mu \mathrm{m}\right)$, the GCM underpredicts the $\mathrm{O}_{3}$ column by about a factor of 2 with respect to SPICAM. A similar picture emerges from the high southern latitudes (Figure 6a), where a good agreement between SPICAM and the GCM is only found for the largest $\mathrm{H}_{2} \mathrm{O}$ columns. For $\mathrm{H}_{2} \mathrm{O}$ values more typical of the southern polar vortex $\left(\mathrm{H}_{2} \mathrm{O}<1 \mathrm{pr}-\mu \mathrm{m}\right)$, the GCM simulation underestimates the $\mathrm{O}_{3}$ column by about a factor of 2. At low latitudes (Figure 7a), the GCM simulation reproduces the absence of anti-correlation between the $\mathrm{H}_{2} \mathrm{O}$ and $\mathrm{O}_{3}$ columns. The largest $\mathrm{O}_{3}$ columns calculated by the GCM are found around aphelion (see Figure 2) but are, on average, lower by a factor of 2 relative to SPICAM.

In summary, there is a general deficit of polar $\mathrm{O}_{3}$ in the LMD GCM when using the nominal kinetics representing the current consensus in gas-phase atmospheric chemistry. This problem was already noted with previous versions of the model (Lefèvre et al., 2008; Clancy et al., 2016), with the UK version of the LMD GCM (Holmes et al., 2018) and to some extent in the GEM-Mars GCM (Daerden et al., 2019). The diagnosis being made here in terms of $\mathrm{O}_{3}-\mathrm{H}_{2} \mathrm{O}$ correlation, we show that the underestimation of $\mathrm{O}_{3}$ is not due to a wet bias in the GCM. We also rule out a strong temperature bias that could significantly affect the chemical reaction rates, based on the general agreement found between the GCM temperatures and the Mars Climate 
Sounder observations in the lower atmosphere (Gilli et al., 2020). Other chemical or physical arguments must therefore be invoked to quantitatively explain the $\mathrm{O}_{3}$ columns observed by SPICAM, at least at polar latitudes. At low latitudes, even a small wet bias in the middle atmosphere (caused for instance by model overestimation of upper level $\mathrm{H}_{2} \mathrm{O}$ supersaturation) could have a large impact on $\mathrm{O}_{3}$ without a noticeable effect on the $\mathrm{H}_{2} \mathrm{O}$ column. Greater caution is therefore required and a comparison of the modeled $\mathrm{H}_{2} \mathrm{O}$ and $\mathrm{O}_{3}$ profiles with those measured by solar occultation will be necessary before drawing robust conclusions. 


\section{Latitude : $60^{\circ} \mathrm{N}-90^{\circ} \mathrm{N}$}
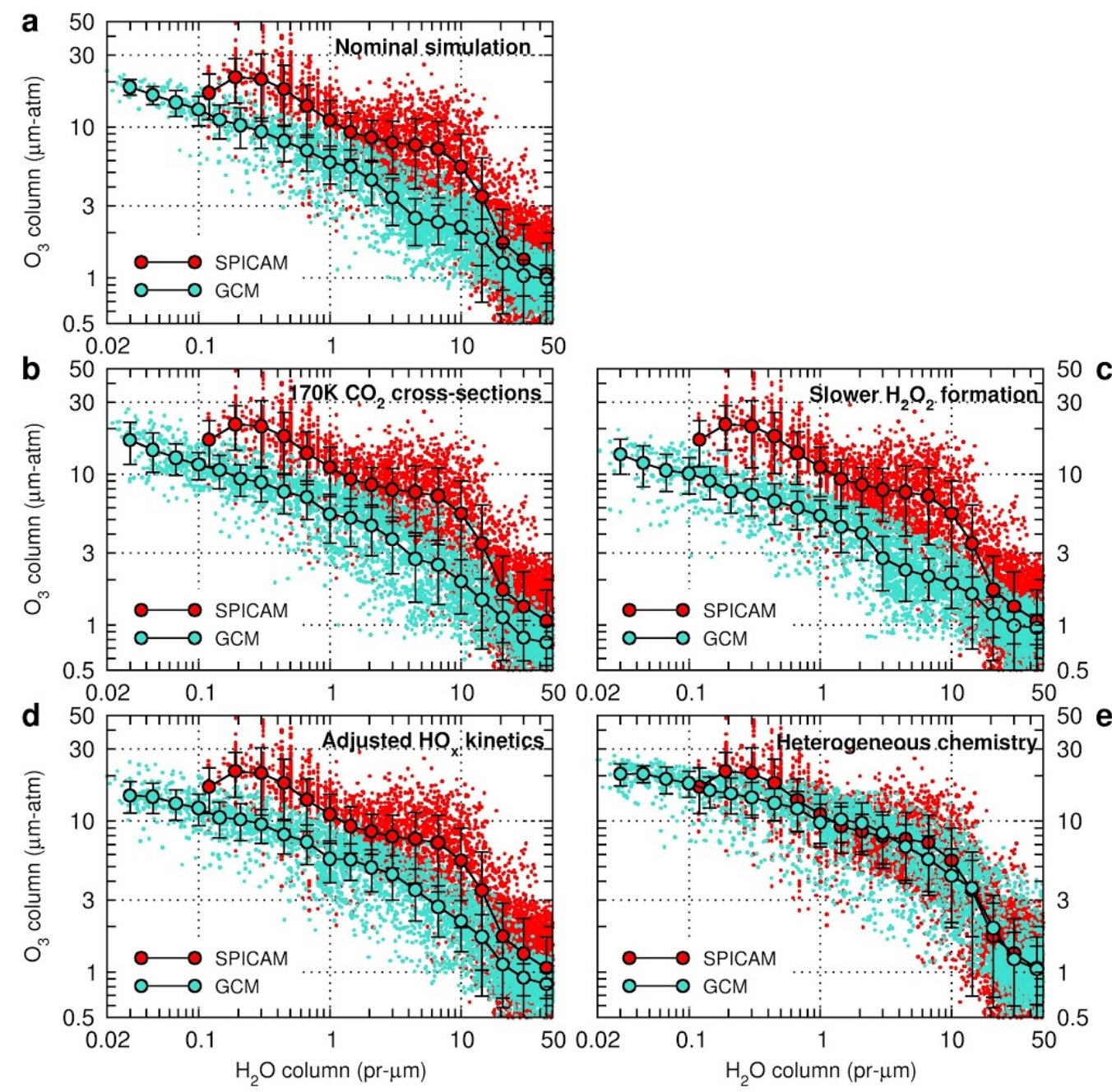

Figure 5. $\mathrm{O}_{3}$ column ( $\left.\mu \mathrm{m}-\mathrm{atm}\right)$ vs. $\mathrm{H}_{2} \mathrm{O}$ column ( $\left.\mathrm{pr}-\mu \mathrm{m}\right)$ measured by SPICAM (red) and calculated by the LMD GCM (turquoise) in the $60^{\circ} \mathrm{N}-90^{\circ} \mathrm{N}$ latitude band, for five simulations. (a) nominal simulation (b) $\mathrm{CO}_{2}$ absorption cross-sections from Venot et al. (2018) (c) $\mathrm{HO}_{2}+\mathrm{HO}_{2}$ $\rightarrow \mathrm{H}_{2} \mathrm{O}_{2}+\mathrm{O}_{2}$ rate coefficient from Christensen et al. (2002) (d) adjusted $\mathrm{HO}_{\mathrm{x}}$ kinetics (e) heterogeneous uptake of $\mathrm{HO}_{x}$ and $\mathrm{H}_{2} \mathrm{O}_{2}$ on water ice clouds. Circles and error bars represent the average and $1-\sigma$ standard deviation. 


\section{Latitude : $60^{\circ} \mathrm{S}-90^{\circ} \mathrm{S}$}


Figure 6. Same as Figure 5 for the $60^{\circ} \mathrm{S}-90^{\circ} \mathrm{S}$ latitude band. Note the change in horizontal scale with respect to Figure 5. 


\section{Latitude : $15^{\circ} \mathrm{N}-15^{\circ} \mathrm{S}$}
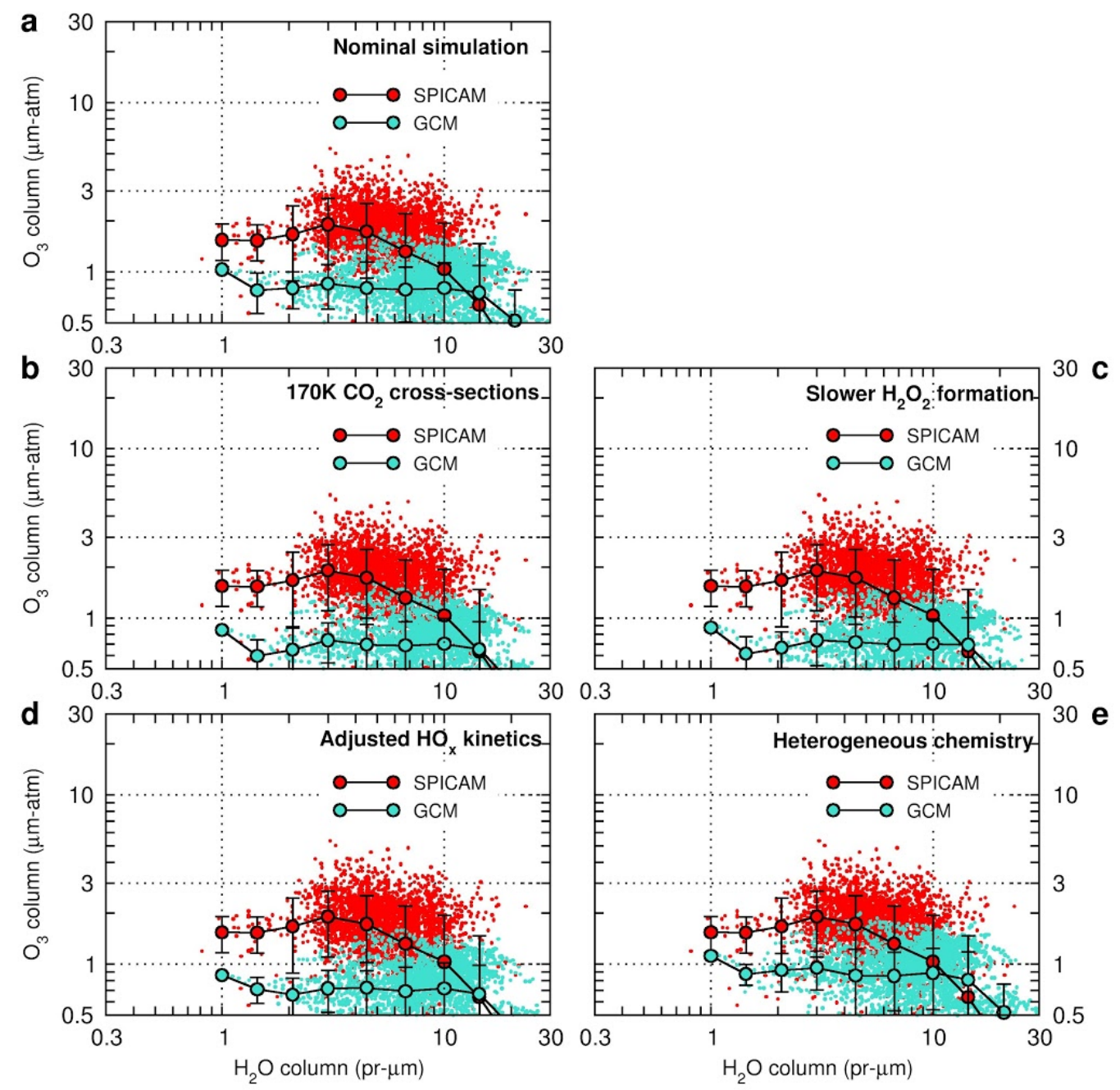

Figure 7. Same as Figure 5 for the $15^{\circ} \mathrm{N}-15^{\circ} \mathrm{S}$ latitude band. Note the change in the horizontal and vertical scales with respect to Figures 4 and 5 . 


\subsection{Ozone formation}

The $\mathrm{O}_{3}$ deficit in the GCM raises the question of a possible underestimation of the $\mathrm{O}_{3}$ formation rate by the reaction:

$$
\mathrm{O}+\mathrm{O}_{2}+\mathrm{CO}_{2} \rightarrow \mathrm{O}_{3}+\mathrm{CO}_{2}
$$

However, this process is well documented by laboratory work and does not suffer from large uncertainties at temperatures of atmospheric interest. Kinetic studies using $\mathrm{CO}_{2}$ as a third body agree within 10\% at ambient temperature (Bevan and Johnson, 1973; Sehested et al., 1995), and the uncertainty on the rate coefficient at $200 \mathrm{~K}$ is estimated to be only around $20 \%$ (Burkholder et al., 2015). Moreover, a change in the rate coefficient of reaction (4) does not affect the total amount of $\mathrm{O}_{x}$ but only shifts the equilibrium between $\mathrm{O}$ and $\mathrm{O}_{3}$ within the $\mathrm{O}_{x}$ family. Even if the rate were to be increased by $20 \%$, this shift would have a marginal impact on the $\mathrm{O}_{3}$ column, since $\mathrm{O}$ is at least one order of magnitude less abundant than $\mathrm{O}_{3}$ in the lower atmosphere. Therefore, the underestimation of the $\mathrm{O}_{3}$ formation rate in the model does not seem to be a viable explanation to explain the discrepancy with SPICAM.

\subsection{Impact of low-temperature $\mathrm{CO}_{2}$ cross-sections}

Absorption cross-sections of $\mathrm{CO}_{2}$ are of great importance in the $\mathrm{O}_{3}$ chemistry since they determine the $\mathrm{O}_{x}$ production by $\mathrm{CO}_{2}$ photolysis as well as the UV flux available to dissociate $\mathrm{H}_{2} \mathrm{O}$. As indicated in section 3.1, the nominal version of the LMD GCM adopts $\mathrm{CO}_{2}$ cross-sections measured at $295 \mathrm{~K}$ and $195 \mathrm{~K}$. Recently, Venot et al. (2018) measured a set of high-resolution $\mathrm{CO}_{2}$ cross-sections at $150 \mathrm{~K}$ and $170 \mathrm{~K}$, offering the possibility to conduct photolysis calculations at temperatures more in line with the Mars polar atmosphere. We have tested the impact of these new measurements by adopting the $\mathrm{CO}_{2}$ cross-sections of Venot et al. (2018) at $170 \mathrm{~K}$ from 115 to $185 \mathrm{~nm}$, extrapolated to $210 \mathrm{~nm}$. In this sensitivity experiment, we did not consider the cross-sections measured at $150 \mathrm{~K}$, due to more uncertain data longward of $177 \mathrm{~nm}$. 
The results obtained with this GCM experiment are compared to SPICAM and to the nominal simulation in Figures 5b-6b-7b. At high and low latitudes, the use of the $\mathrm{CO}_{2}$ cross-sections at $170 \mathrm{~K}$ leads, on average, to a $-10 \%$ to $-20 \%$ decrease in the $\mathrm{O}_{3}$ column with respect to the nominal simulation. This effect can be attributed to the lower UV opacity of $\mathrm{CO}_{2}$ at $170 \mathrm{~K}$, leading to a larger $\mathrm{H}_{2} \mathrm{O}$ photolysis rate and $\mathrm{HO}_{x}$ production. Therefore, although low-temperature $\mathrm{CO}_{2}$ cross-sections are obviously desirable and will be included as standard in future versions of the GCM, they are not the solution to the underestimation of $\mathrm{O}_{3}$ and rather tend to aggravate this bias in the model.

\subsection{Sensitivity to the $\mathrm{HO}_{2}+\mathrm{HO}_{2}$ reaction rate}

As mentioned earlier, reaction (2) between $\mathrm{H}_{2}$ and $\mathrm{O}\left({ }^{1} \mathrm{D}\right)$ is the main source of $\mathrm{HO}_{\mathrm{x}}$ in the winter polar vortices, but this source is low. We have tested a 30\% decrease in its efficiency, corresponding to the uncertainty on the measured $\mathrm{H}_{2}$ mixing ratio (Krasnopolsky and Feldman, 2001), and found a negligible impact on the model results (not shown). On the other hand, we noticed that in the polar regions, the amount of modeled $\mathrm{O}_{3}$ is sensitive to the reaction that forms hydrogen peroxide $\left(\mathrm{H}_{2} \mathrm{O}_{2}\right)$ :

$$
\mathrm{HO}_{2}+\mathrm{HO}_{2} \rightarrow \mathrm{H}_{2} \mathrm{O}_{2}+\mathrm{O}_{2}
$$

Indeed, in dehydrated conditions, this reaction largely determines the quantity of $\mathrm{HO}_{2}$ that is either available to destroy $\mathrm{O}_{x}$ by reaction (3), or sequestered in the short-lived $(\sim 6 \mathrm{~h})$ reservoir $\mathrm{H}_{2} \mathrm{O}_{2}$. Unfortunately, systematic discrepancies exist in the low-temperature rate coefficient data for reaction (5), and their extrapolation to Martian temperatures is uncertain. At $180 \mathrm{~K}$, the rate coefficient used in our nominal simulation, taken from the JPL 2015 recommendation (Burkholder et al., 2015), is 40\% lower than the JPL 2003 recommendation employed in the GEM-Mars GCM (Daerden et al., 2019). On the other hand, at $180 \mathrm{~K}$, the JPL 2015 rate coefficient is twice as high as the rate derived by Christensen et al. (2002), previously used in the LMD GCM (Lefèvre et al., 2004). The use in photochemical models of a fast $\mathrm{H}_{2} \mathrm{O}_{2}$ formation rate at low temperatures, such as that of JPL 2003, does not seem recommended as it leads to a strong overestimation of $\mathrm{H}_{2} \mathrm{O}_{2}$ in the terrestrial stratosphere (Versick et al., 2012). By contrast, a 
slow $\mathrm{H}_{2} \mathrm{O}_{2}$ formation rate at low temperatures, such as that of Christensen et al. (2002), cannot be ruled out with the current data at hand. We have tested this possibility in a dedicated GCM experiment.

Figures 5c-6c-7c show that the use of the expression derived by Christensen et al. (2002) for reaction (5) leads at all latitudes to a decrease in $\mathrm{O}_{3}$ with respect to the nominal simulation. The change in the $\mathrm{O}_{3}$ column is of the order of $-10 \%$ for $10 \mathrm{pr}-\mu \mathrm{m}$ of $\mathrm{H}_{2} \mathrm{O}$ and $-20 \%$ to $-30 \%$ for $\mathrm{H}_{2} \mathrm{O}$ columns below $1 \mathrm{pr}-\mu \mathrm{m}$. The amount of $\mathrm{O}_{3}$ calculated in the polar vortices is therefore quite sensitive to the rate coefficient of reaction (5), which emphasizes the need for a more accurate laboratory determination at low temperatures. In the light of our results, however, it seems unlikely that better knowledge of this rate coefficient is the solution to the underestimation of $\mathrm{O}_{3}$ by the GCM. On the contrary, in case new laboratory measurements confirm that the low-temperature rate coefficient of reaction (5) is slower than that currently recommended by the JPL, a worsening of the $\mathrm{O}_{3}$ deficit is expected in the model.

\subsection{Adjusted $\mathrm{HO}_{\mathrm{x}}$ kinetics}

The chemistry of $\mathrm{O}_{3}$ on Mars shows great similarities with that of the middle atmosphere on Earth, where at comparable temperatures and pressures, $\mathrm{HO}_{\mathrm{x}}$ radicals are also the main catalysts of odd oxygen (Brasseur and Solomon, 2005). Despite this simple photochemistry, there is ample literature showing discrepancies between observed and simulated $\mathrm{HO}_{\mathrm{x}}$ concentrations in the terrestrial stratosphere and mesosphere (see the review in Li et al., 2017). Laboratory uncertainties of chemical kinetics rates have often been put forward to explain these disagreements. We have explored this possibility by adopting the adjustments of kinetic rates of some important photochemical reactions determined by Li et al. (2017), who used an optimal estimation approach to better fit the simulated $\mathrm{HO}_{\mathrm{x}}$ with the observations. Following their simulation with constrained $\mathrm{H}_{2} \mathrm{O}$ and $\mathrm{O}_{3}$ profiles in the Earth stratosphere and mesosphere, we have multiplied the kinetic rate coefficients of the following three reactions

$$
\begin{array}{ll}
\mathrm{H}+\mathrm{O}_{2}+\mathrm{CO}_{2} & \rightarrow \mathrm{HO}_{2}+\mathrm{CO}_{2} \\
\mathrm{O}+\mathrm{OH} & \rightarrow \mathrm{O}_{2}+\mathrm{H}
\end{array}
$$




$$
\mathrm{OH}+\mathrm{HO}_{2} \quad \rightarrow \mathrm{H}_{2} \mathrm{O}+\mathrm{O}_{2}
$$

by a factor of $3.1,1.12$, and 0.9 , respectively. The results of the GCM simulation with this adjusted $\mathrm{HO}_{\mathrm{x}}$ kinetics are shown in Figures $5 \mathrm{~d}-6 \mathrm{~d}-7 \mathrm{~d}$. At high latitudes, the impact on the $\mathrm{O}_{3}$ column is in general negative (except for $\mathrm{H}_{2} \mathrm{O}$ columns between 1 and $10 \mathrm{pr}-\mu \mathrm{m}$ at $60^{\circ} \mathrm{N}-90^{\circ} \mathrm{N}$ ), with about a $10 \%$ decrease relative to the nominal experiment. At $15^{\circ} \mathrm{N}-15^{\circ} \mathrm{S}$, the $\mathrm{O}_{3}$ column calculated with the adjusted $\mathrm{HO}_{\mathrm{x}}$ kinetics is on average $15 \%$ lower and hence further away from the SPICAM measurements. This result does not call into question the need for future laboratory measurements to improve the knowledge of the $\mathrm{HO}_{\mathrm{x}}$ kinetics, which is still very incomplete at temperatures and pressures relevant to Mars and the Earth's middle atmosphere. However, in the current state of knowledge, the adjustments in the kinetics recently proposed in the framework of terrestrial studies seem unlikely to lead to a significant improvement in Martian $\mathrm{O}_{3}$ modeling.

\subsection{Heterogeneous chemistry}

To explain the discrepancy between the $\mathrm{O}_{3}$ column measured by SPICAM and an earlier version of the LMD GCM, Lefèvre et al. (2008) proposed to consider the uptake of $\mathrm{OH}$ and $\mathrm{HO}_{2}$ on water-ice clouds as measured in laboratory (Cooper and Abbatt, 1996). The inclusion of these heterogeneous reactions in the model led to an improved agreement with the $\mathrm{O}_{3}$ measurements. Based on MARCI observations, the evidence of heterogeneous chemistry was later put into question by Clancy et al. (2016), who noted largely overestimated cloud optical depths in the GCM and the absence of correlation between clouds and $\mathrm{O}_{3}$ in the MARCI data. With its increased vertical resolution and reduced physical timestep (Vals et al., 2018), the present configuration of the LMD GCM simulates polar hoods that are $\sim 4$ times less opaque than in the version compared to MARCI (Clancy et al., 2016; Wolff et al., 2019) and TES (Holmes et al., 2018) observations. This change greatly reduces the difference between the model and the observations and justifies a new assessment of the impact of heterogeneous chemistry on the modeled $\mathrm{O}_{3}$ layer.

Figures 5e-6e-7e display the $\mathrm{O}_{3}-\mathrm{H}_{2} \mathrm{O}$ relation obtained from a GCM experiment that incorporates the uptake of $\mathrm{HO}_{\mathrm{x}}$ on water-ice clouds (Cooper and Abbatt, 1996), as well as the reversible 
uptake of $\mathrm{H}_{2} \mathrm{O}_{2}$ on ice measured by Pouvesle et al. (2010). In the $60^{\circ} \mathrm{N}-90^{\circ} \mathrm{N}$ band, the $\mathrm{O}_{3}$ columns are significantly increased for all values of $\mathrm{H}_{2} \mathrm{O}$. For $\mathrm{H}_{2} \mathrm{O}$ columns between 1 and 15 pr- $\mu \mathrm{m}$, the doubling of the $\mathrm{O}_{3}$ column leads to an excellent agreement with SPICAM. In this range of $\mathrm{H}_{2} \mathrm{O}$ columns, the GCM run with heterogeneous chemistry is also the only simulation that correctly reproduces the shoulder observed in the $\mathrm{O}_{3}-\mathrm{H}_{2} \mathrm{O}$ relationship. For $\mathrm{H}_{2} \mathrm{O}<1$ pr- $\mu$ m, a distinct increase in $\mathrm{O}_{3}$ is calculated but the largest columns observed by SPICAM ( $>30 \mu \mathrm{m}$-atm) are still out of reach of the model. This contrasts with the results obtained with the previous version of the LMD GCM (Clancy et al., 2016), which shows an impact of heterogeneous chemistry generally too strong in northern spring, likely to be due to overestimated cloud surface areas. Another consequence of the decreased polar hood opacity in the current simulation is the absence of correlation between the modeled $\mathrm{O}_{3}$ column and cloud optical depth (not shown), a result now in line with MARCI observations.

The uptake of $\mathrm{HO}_{x}$ and $\mathrm{H}_{2} \mathrm{O}_{2}$ on clouds also leads to a general $\mathrm{O}_{3}$ increase at high southern latitudes (Figure 6e). As in the Northern Hemisphere, a good agreement with SPICAM is found for all $\mathrm{H}_{2} \mathrm{O}$ columns larger than $1 \mathrm{pr}-\mu \mathrm{m}$. Below that value, the improvement over the nominal simulation is less pronounced. In the dehydrated vortex, the effect of heterogeneous chemistry as implemented in the GCM is not sufficient to match the SPICAM $\mathrm{O}_{3}$ columns, which are still larger than in the simulation by about a factor of two.

At low latitudes (Figure 7e), the heterogeneous chemistry only leads to a moderate increase of about $10 \%$ in the $\mathrm{O}_{3}$ column. The peak $\mathrm{O}_{3}$ columns modeled around aphelion are still largely underestimated relative to SPICAM. This confirms previous results (Lefèvre et al., 2008; Clancy et al., 2016) suggesting that the extent or the surface area of the aphelion cloud belt in the model is too small for heterogeneous chemistry to significantly alter the $\mathrm{O}_{3}$ column at low latitudes.

In summary, heterogeneous chemistry has the potential to quantitatively explain much of the $\mathrm{O}_{3}-\mathrm{H}_{2} \mathrm{O}$ relationship observed by SPICAM at high latitudes. However, this result should be considered with caution. First, water ice clouds on Mars are notoriously difficult to simulate accurately, and the current knowledge of heterogeneous processes in Martian conditions is poor. Our assessment is therefore subject to considerable uncertainty. Second, the uptake of $\mathrm{HO}_{\mathrm{x}}$ and 
$\mathrm{H}_{2} \mathrm{O}_{2}$ on ice seems unable to explain the largest $\mathrm{O}_{3}$ columns measured by SPICAM in the core of the sunlit vortices. Even if one admits that heterogeneous chemistry is effective in the Martian atmosphere, it does not seem to be a single answer to the lack of $\mathrm{O}_{3}$ in the GCM.

\section{Discussion and perspectives}

We have characterized the relationship between the $\mathrm{O}_{3}$ and $\mathrm{H}_{2} \mathrm{O}$ columns from four Martian years of observation by SPICAM. A distinct anti-correlation between both species is found at high latitudes, where the $\mathrm{O}_{3}$ column varies roughly with the -0.6 power of the $\mathrm{H}_{2} \mathrm{O}$ column. By contrast, there is no clear anti-correlation at low latitudes, confirming earlier model predictions (Lefèvre et al., 2004) that the vertically-integrated $\mathrm{H}_{2} \mathrm{O}$ column is not the parameter determining the $\mathrm{O}_{3}$ column in these regions.

These main features of the $\mathrm{O}_{3}-\mathrm{H}_{2} \mathrm{O}$ relation are qualitatively well reproduced by the LMD GCM. Other peculiarities revealed by SPICAM, such as the absence of tight anti-correlation inside the northern polar vortex, or the three-fold lower $\mathrm{O}_{3}$ columns in the Southern Hemisphere for the same amount of $\mathrm{H}_{2} \mathrm{O}$, are also present in our GCM simulations.

The quantitative agreement between our model and SPICAM is less satisfactory. In its nominal configuration, representative of the conventional chemistry recommended for terrestrial and planetary studies, our model underestimates the $\mathrm{O}_{3}$ column by about a factor of two. This problem being diagnosed for the same amounts of $\mathrm{H}_{2} \mathrm{O}$ in the GCM and by SPICAM, modeling biases in the $\mathrm{H}_{2} \mathrm{O}$ column cannot provide a valid explanation. Consequently, the lack of ozone in the model is more likely related to an inaccurate description of the photochemistry that links $\mathrm{H}_{2} \mathrm{O}$ to $\mathrm{O}_{3}$. Whatever the underlying cause, this is an indication that the mechanisms of $\mathrm{O}_{3}$ destruction by the $\mathrm{HO}_{\mathrm{x}}$ radicals are too efficient in the GCM. This hypothesis seems to be corroborated by the fact that all current Martian models severely underestimate the long-term equilibrium value of CO (Lefèvre and Krasnopolsky, 2017), which also points to an overprediction of the oxidation by $\mathrm{HO}_{\mathrm{x}}$ in the models. On the other hand, GCMs reproduce reasonably well the observed

seasonal cycle of $\mathrm{H}_{2} \mathrm{O}_{2}$ (Encrenaz et al., 2015; Daerden et al., 2019), which is not indicative of a major issue in the amount of modeled $\mathrm{HO}_{\mathrm{x}}$. This result mostly obtained at low-to-mid latitudes 
needs to be confirmed by a better determination of the kinetics of $\mathrm{H}_{2} \mathrm{O}_{2}$ formation at Martian temperatures.

It is also tantalizing to relate the lack of $\mathrm{O}_{3}$ in our Martian GCM to the long-standing 'ozone deficit problem' in the models of the Earth mesosphere and upper stratosphere (e.g., Siskind et al., 2013). Since the same $\mathrm{HO}_{\mathrm{x}}$ chemistry is supposed to be involved in both cases, the ozone deficit noted in the Martian and terrestrial models could have the same origin. In the same spirit as terrestrial studies, we have tested the adjustment of some key reaction rates but found no significant impact on our results. Nevertheless, the choice of reactions to be adjusted is not unique, there are large gaps in the kinetics database at temperatures relevant to Mars, and alternative chemical processes have not yet been measured (Li et al., 2017). Investigating the uncertainties in the kinetics and their impact on Mars photochemistry is therefore an area of future work, which should be conducted in a coordinated manner with mesospheric studies on Earth. Direct measurements of $\mathrm{OH}$ and $\mathrm{HO}_{2}$ in the Mars lower atmosphere would also be of great value to constrain the $\mathrm{HO}_{\mathrm{x}}$ photochemistry in the models.

The uptake of $\mathrm{HO}_{x}$ on ice clouds is an attractive possibility to reduce the oxidizing capacity of the atmosphere and the efficiency of the $\mathrm{HO}_{x}$-catalyzed loss of $\mathrm{O}_{3}$. Experimental data are sparse but this process has been identified in the laboratory, and rare measurements in cirrus clouds have pointed to the role of ice crystals as sinks of $\mathrm{HO}_{\mathrm{x}}$ (e.g., Jaeglé et al., 2000). When implemented in the latest version of our GCM, heterogeneous chemistry has a positive impact on the results although it is not sufficient to match the largest $\mathrm{O}_{3}$ columns measured by SPICAM. This partial success must be tempered by the large uncertainties that exist in the seasonality of ice clouds in the model, their geographical extent, and their microphysical characteristics. Nevertheless, heterogeneous chemistry has clearly the potential to solve at least partly the discrepancy with the SPICAM data. A more robust conclusion will likely require a detailed validation of the polar hoods simulated by the GCM.

Finally, it must be kept in mind that owing to the nadir geometry, our results mostly concern the lowest scales height of the Mars atmosphere. The next step is to investigate the $\mathrm{O}_{3}-\mathrm{H}_{2} \mathrm{O}$ relation as a function of altitude, which is key to understanding the photochemistry of the middle 
atmosphere and in particular the absence of anti-correlation between the $\mathrm{O}_{3}$ and $\mathrm{H}_{2} \mathrm{O}$ columns at low latitudes. Such studies can be conducted with SPICAM in its solar occultation mode. Future work will exploit the simultaneous retrievals of the $\mathrm{O}_{3}$ and $\mathrm{H}_{2} \mathrm{O}$ profiles that are performed at sunrise and sunset (Määttänen et al., 2018; Fedorova et al., 2021), in conjunction with the nadir data presented here. The most promising prospect for the coming years is offered by the NOMAD instrument on board the Exomars Trace Gas Orbiter, which is providing simultaneous profiles of $\mathrm{O}_{3}$ and $\mathrm{H}_{2} \mathrm{O}$ with high vertical resolution and unprecedented temporal cadence (Vandaele et al., 2018). Provided that the large $\mathrm{O}_{3}$ variations at sunrise and sunset are carefully accounted for, these measurements should lead to major advances in our quantitative understanding of Martian photochemistry.

\section{Acknowledgements.}

We thank Frank Daerden and an anonymous reviewer for their helpful comments on the manuscript. We also thank Todd Clancy for his valuable remarks on the first version of the article. The SPICAM team at LATMOS and LMD gratefully acknowledges CNES for the continuous funding since the beginning of the mission, and the Programme National de Planétologie (PNP) for support of the present analysis.

\section{Data availability statement}

The SPICAM and model data presented in this paper are available in this in-text data citation reference: Lefèvre (2021). SPICAM raw and calibrated data are available in the ESA Planetary $\begin{array}{llll}\text { Science } & \text { Archives } & \text { (PSA) https://archives. }\end{array}$ esac.esa.int/psa/\#!Table\%20View/SPICAM=instrument. 


\section{References}

Angelats i Coll, M., Forget, F., López-Valverde, M. A., \& González-Galindo F. (2005). The first Mars thermospheric general circulation model: The Martian atmosphere from the ground to $240 \quad \mathrm{~km} . \quad$ Geophysical Research Letters, 32, L04201. https://doi.org/10.1029/2004GL021368

Barth, C. A., \& Hord, C. W. (1971). Mariner Ultraviolet Spectrometer: Topography and polar cap. Science, 173, 201.

Barth, C. A., Hord, C. W., Stewart, A. I., Lane, A. L., Dick, M. L., \& Anderson, G. P. (1973). Mariner 9 ultraviolet spectrometer experiment: seasonal variation of ozone on Mars. Science, 179, 795-796.

Bertaux, J.-L., Korablev, O., Perrier, S., Quémerais, E., Montmessin, F., Leblanc, F., et al. (2006). SPICAM on Mars Express: observing modes and overview of UV spectrometer data and scientific results. Journal of Geophysical Research, 111, 10. doi:10.1029/2006JE002690

Bevan, P. L. T., \& Johnson, G. R. A. (1973). Kinetics of ozone formation in the pulse radiolysis of oxygen gas. Journal of the Chemical Society, Faraday Transactions, 1, 69, 216-227.

Brasseur, G. P., \& Solomon, S. (2005). Aeronomy of the Middle Atmosphere: Chemistry and Physics of the Stratosphere and Mesosphere (3rd ed.). (pp. 646). Dordrecht, Netherlands: Springer.

Burkholder, J. B., Sander, S. P., Abbatt, J., Barker, J. R., Huie, R. E., Kolb, C. E., et al. (2015). Chemical kinetics and photochemical data for use in atmospheric studies, Evaluation No. 18, JPL Publication 15-10, Pasadena, CA: Jet Propulsion Laboratory. 
Cariolle, D., Moinat, P., Teyssèdre, H., Giraud, L., Josse, B., \& Lefèvre, F. (2017). ASIS v1.0: an adaptive solver for the simulation of atmospheric chemistry. Geoscientific Model Development, 10, 1467-1485, doi:10.5194/gmd-10-1467-2017

Chung, C. Y., Chew, E. P., Cheng, B. M., Bahou, M., \& Lee, Y. P. (2001) Temperature dependence of absorption cross-section of $\mathrm{H}_{2} \mathrm{O}, \mathrm{HDO}$, and $\mathrm{D}_{2} \mathrm{O}$ in the spectral region 140-193 nm. Nuclear Instruments and Methods in Physics Section A: Accelerators, Spectrometers, Detectors and Associated Equipment, 467, 1572-1576. https://doi.org/10.1016/S0168-9002(01)00762-8

Christensen, L. E., Okumora, M., Sander, S. P., Salawitch, R. J., Toon, G. C., B. Sen, B., et al. (2002). Kinetics of $\mathrm{HO}_{2}+\mathrm{HO}_{2} \rightarrow \mathrm{H}_{2} \mathrm{O}_{2}+\mathrm{O}_{2}$ : Implications for stratospheric $\mathrm{H}_{2} \mathrm{O}_{2}$. Geophysical Research Letters, 29(9), 1299. doi:10.1029/2001GL014525

Clancy, R. T., \& Nair, H. (1996). Annual (perihelion-aphelion) cycles in the photochemical behavior of the global Mars atmosphere. Journal of Geophysical Research, 101, $12,785-12,790$.

Clancy, R. T., Wolff, M. J., \& James, P. B. (1999). Minimal aerosol loading and global increases in atmospheric ozone during the 1996-1997 Martian northern spring season. Icarus, 138, 49-63.

Clancy, R. T., Wolff, M. J., Lefèvre, F., Cantor, B. A., Malin, M. C., \& Smith, M. D. (2016). Daily global mapping of Mars ozone column abundances with MARCI UV band imaging. Icarus, 266, 112-133. http://dx.doi.org/10.1016/j.icarus.2015.11.016

Clancy, R. T., Smith, M. D., Lefèvre, F., McConnochie, T. H., Sandor, B. J., Wolff, M. J., et al. (2017). Vertical profiles of $1.27 \mu \mathrm{m} \mathrm{O}_{2}$ dayglow from MRO CRISM limb spectra : Seasonal/global behaviors, comparisons to LMDGCM simulations, and a global definition for water vapor profiles, Icarus, 293, 132-156. 
Colaïtis, A., Spiga, A., Hourdin, F., Rio, C., Forget, F., \& Millour, E. (2013). A thermal plume model for the Martian convective boundary layer. Journal of Geophysical Research: Planets, 118, 1468-1487. https://doi.org/10.1002/jgre.20104

Cooper, P. L., \& Abbatt, J. P. D. (1996). Heterogeneous interactions of $\mathrm{OH}$ and $\mathrm{HO}_{2}$ radicals with surfaces characteristic of atmospheric particulate matter. Journal of Physical Chemistry, $100,2249-2254$.

Daerden, F., Neary, L., Viscardy, S., García Muñoz, A., Clancy, R.T., Smith, M.D., et al. (2019). Mars atmospheric chemistry simulations with the GEM-Mars general circulation model. Icarus, 326, 197-224. http://dx.doi.org/ 10.1016/j.icarus.2019.02.030

Encrenaz, T., Greathouse, T. K., Lefèvre, F., Montmessin, F., Forget, F., Fouchet, T., et al. (2015). Seasonal variations of hydrogen peroxide and water vapor on Mars: further indications of heterogeneous chemistry. Astronomy and Astrophysics, 578, A127. https://doi.org/10.1051/0004- 6361/201425448

Fast, K., Kostiuk, T., Espenak, F., Annen, J., Buhl, D., Hewagama, T., et al. (2006). Ozone abundance on Mars from infrared heterodyne spectra. I. Acquisition, retrieval, and anticorrelation with water vapor, Icarus, 181, 419-431. doi:10.1016/j.icarus.2005.12.001

Fedorova, A., Korablev, O., Bertaux, J.-L., Rodin, A., Kiselev, A., \& Perrier, S. (2006). Mars water vapor abundance from SPICAM IR spectrometer: seasonal and geographic distributions. Journal of Geophysical Research, 111, E09S08. doi:10.1029/2006JE002695

Fedorova, A., Montmessin, F., Korablev, O., Lefèvre, F., Trokhimovskiy, A., \& Bertaux, J. -L. (2021). Multi-annual monitoring of the water vapor vertical distribution on Mars by SPICAM on Mars Express. Journal of Geophysical Research, 126. doi: 10.1029/2020JE006616 
Forget, F., Hourdin, F., Fournier, R., Hourdin, C., Talagrand, O., Collins, M., et al. (1999). Improved general circulation models of the Martian atmosphere from the surface to above 80 km. Journal of Geophysical Research, 104, 24,155-24,175.

Gilli, G., Forget, F., Spiga, A., Navarro, T., Millour, E., Montabone, L., et al. (2020). Impact of gravity waves on the middle atmosphere of Mars: A non-orographic gravity wave parameterization based on global climate modeling and MCS observations. Journal of Geophysical Research: Planets, 125, e2018JE005873. https://doi.org/10.1029/2018JE005873

González-Galindo, F., Forget, F., López-Valverde, M. A., Angelats i Coll, M., \& Millour, E. (2009). A ground-to-exosphere martian general circulation model: 1. Seasonal, diurnal, and solar cycle variation of thermospheric temperatures. Journal of Geophysical Research: Planets, 114, E04001. https://doi.org/10.1029/2008JE003246

González-Galindo, F., López-Valverde, M. A., Angelat i Coll, M., \& Forget, F. (2005). Extension of a Martian general circulation model to thermospheric altitudes: UV heating and photochemical models. Journal of Geophysical Research, 110, E09008. https://doi.org/10.1029/2004JE002312

González-Galindo, F., Chaufray, J. Y., López-Valverde, M. A., Gilli, G., Forget, F., Leblanc, F., et al. (2013). 3D Martian ionosphere model: I. The photochemical ionosphere below $180 \mathrm{~km}$. Journal of Geophysical Research: Planets, 118, 2105-2123. https://doi.org/10.1002/jgre.20150

Gröller, H., Montmessin, F., Yelle, R. V., Lefèvre, F., Forget, F., Schneider, N. M., et al. (2018). MAVEN/IUVS stellar occultation measurements of Mars atmospheric structure and composition. Journal of Geophysical Research: Planets, 123, 1449-1483. https://doi.org/10.1029/2017JE005466 
Guslyakova, S., Fedorova, A., Lefèvre, F., Korablev, O., Montmessin, F., Trokhimovsky, A., \& Bertaux, J.-L. (2016). Long-term nadir observations of the $\mathrm{O}_{2}$ dayglow by SPICAM IR. Planetary Space Science, 122, 1-12. doi:10.1016/j.pss.2015.12.006.

Holmes, J. A., Lewis, S. R., Patel, M. R., \& Lefèvre, F. (2018). A reanalysis of ozone on Mars from assimilation of SPICAM observations. Icarus, 302, 308-318. https://doi.org/10.1016/j.icarus.2019.03.016

Huestis, D. L., \& Berkowitz, J. (2010). Critical evaluation of the photoabsorption cross section of $\mathrm{CO}_{2}$ from 0.125 to $201.6 \mathrm{~nm}$ at room temperature. In: AAS/Division for Planetary Sciences Meeting Abstracts \#42. p. 48.13.

Ityaksov, D., Linnartz, H., \& Ubachs, W. (2008). Deep-UV absorption and Rayleigh scattering of carbon dioxide. Chemical Physics Letters, 462(1-3), 31-34.

Jaeglé, L., Jacob, D. J., Brune, W. H., Faloona, I., Tan, D., Heikes, B. G., et al. (2000). Photochemistry of HOx in the upper troposphere at northern midlatitudes. Journal of Geophysical Research, 105, 3877-3892.

Korablev, O., Bertaux, J.-L., Fedorova, A., Fonteyn, D., Stepanov, A., Kalinnikov, Y. et al. (2006). SPICAM IR acousto-optic spectrometer experiment on Mars Express. Journal of Geophysical Research: Planets, 111(E9), E09S03. doi: 10.1029/2006je002696

Krasnopolsky, V. A., \& Feldman, P. D. (2001). Detection of molecular hydrogen in the atmosphere of Mars. Science, 294, 1914-1917.

Lebonnois, S, Quémerais, E., Montmessin, F., Lefèvre, F., Perrier, S., Bertaux, J.-L., \& Forget, F. (2006). Vertical distribution of ozone on Mars as measured by SPICAM/Mars Express using stellar occultations. Journal of Geophysical Research, 111, E09S05. https://doi.org/10.1029/2005JE002643 
Lefèvre, F. (2021). Dataset in support of paper "Relationship between the Ozone and Water Vapor columns on Mars as Observed by SPICAM and Calculated by a Global Climate Model" [Data set]. Mendeley. https://doi.org/10.17632/FNGS4KJ27V

Lefèvre, F., Bertaux, J.-L., Clancy, R. T., Encrenaz, T., Fast, K., Forget, F., et al. (2008). Heterogeneous chemistry in the atmosphere of Mars. Nature, 454, 971-975. doi:10.1038/nature07116

Lefèvre, F., \& Krasnopolsky, V. A. (2017). Atmospheric photochemistry. In R. Haberle, R. T. Clancy, F. Forget, M. Smith, \& R. W. Zurek (Eds.), The Atmosphere and Climate of Mars (pp. 405-432). Cambridge: Cambridge University Press. https://doi.org/10.1017/9781139060172.013

Lefèvre, F., Lebonnois, S., Montmessin, F., \& Forget, F. (2004). Three-dimensional modeling of ozone on Mars. Journal of Geophysical Research, 109, E07004. https://doi.org/10.1029/2004JE002268

Li, K.-F., Zhang, Q., Wang, S., Sander, S. P., \& Yung, Y. L. (2017). Resolving model-observation discrepancy in the mesospheric and stratospheric $\mathrm{HO}_{\mathrm{x}}$ chemistry. Earth and Space Science, 4, 607-624. https://doi.org/10.1002/2017EA000283

Lin, Z., Stamnes, S., Jin, Z., Laszlo, I., Tsay, S.-C., Wiscombe, W. J., et al. (2015). Improved discrete ordinate solutions in the presence of an anisotropically reflecting lower boundary: Upgrades of the DISORT computational tool. Journal of Quantitative Spectroscopy \& Radiative Transfer, 157, 119-134. http://dx.doi.org/10.1016/j.jqsrt.2015.02.014

Lindner, B. L. (1988). Ozone on Mars: the effects of clouds and airborne dust. Planetary Space Science, 36 (2), 125-144. 
Määttänen, A., Lefèvre, F., Guilbon, S., Listowski, C., \& Montmessin, F. (2018). Ozone vertical distribution on Mars from SPICAN/MEXUV occultations. Paper presented at the Scientific Workshop: "From Mars Express to ExoMars", ESAC, Madrid, Spain.

Madeleine, J. -B., Forget, F., Millour, E., Montabone, L., \& Wolff, M. J. (2011). Revisiting the radiative impact of dust on Mars using the LMD Global Climate Model. Journal of Geophysical Research, 116, E11010. doi:10.1029/2011JE003855

Madeleine, J.-B., Forget, F., Millour, E., Navarro, T., \& Spiga, A. (2012). The influence of radiatively active water ice clouds on the Martian climate. Geophysical Research Letters, 39, L23202, doi:10.1029/2012GL053564

Madronich, S., \& Flocke, S. (1998). The Role of Solar Radiation in Atmospheric Chemistry. (pp. 1-26), New York: Springer-Verlag.

Maltagliati, L., Montmessin, F., Fedorova, A., Korablev, O., Forget, F., \& Bertaux, J.-L. (2011). Evidence of water vapor in excess of saturation in the atmosphere of Mars. Science, 333, 1868-1871. doi:10.1126/science. 1207957

McClintock, W. E., G. J. Rottman, \& T. N. Woods. (2005). Solar-stellar irradiance comparison experiment II (SOLSTICE II) : instrument concept and design. Solar Physics, 230, 225-258.

McElroy, M. B., \& Donahue, T. M. (1972). Stability of the Martian atmosphere. Science, 177, 986-988.

Montmessin, F., Korablev, O., Lefèvre, F., Bertaux, J. L., Fedorova, A., Trokhimovskiy, A., et al. (2017). SPICAM on Mars Express: A 10-year in-depth survey of the Martian atmosphere. Icarus, 297, 195-216. https://doi.org/10.1016/j.icarus.2017.06.022 
Montmessin, F., Rannou, P., \& Cabane, M. (2002). New insights into Martian dust distribution and water-ice cloud microphysics, Journal of Geophysical Research, 107, E6, 5037, doi:10.1029/2001JE001520.

Mota, R., Parafita, R., Giuliani, A., Hubin-Franskin, M., Lourenco, J., Garcia, G., et al. (2005). Water VUV electronic state spectroscopy by synchrotron radiation. Chemical Physics Letters, 416 (1-3), 152-159.

Navarro, T., Madeleine, J.-B., Forget, F., Spiga, A., Millour, E., Montmessin, F., et al. (2014). Global climate modeling of the martian water cycle with improved microphysics and radiatively active water ice clouds. Journal of Geophysical Research, 119, 1479-1495. https://doi.org/10.1002/2013JE004550

Olsen, K. S., Lefèvre, F., Montmessin, F. , Fedorova, A., Trokhimovskiy, A., Baggio, L., et al. (2020a). The vertical structure of CO in the martian atmosphere as observed by ACS on ExoMars TGO. Nature Geoscience, in press. doi: 10.1038/s41561-020-00678-w

Olsen, K. S., Lefèvre, F., Montmessin, F., Trokhimovskiy, A., Baggio, L., Fedorova, A., et al. (2020b). First detection of ozone in the mid-infrared at Mars: implications for methane detection. Astronomy \& Astrophysics, $\quad 639, \quad$ A141. https://doi.org/10.1051/0004-6361/202038125

Parkinson, T. D., \& Hunten, D. M. (1972). Spectroscopy and aeronomy of $\mathrm{O}_{2}$ on Mars, Journal of Atmospheric Science, 29, 1380-1390.

Parkinson, W. H., Rufus, J., \& Yoshino, K. (2003). Absolute absorption cross section measurements of $\mathrm{CO} 2$ in the wavelength region 163-200 $\mathrm{nm}$ and the temperature dependence. Chemical Physics, 290, 251-256.

Perrier, S., Bertaux, J.-L., Lefèvre, F., Lebonnois, S., Korablev, O., Fedorova, A., \& Montmessin, F. (2006). Global distribution of total ozone on Mars from SPICAM/MEX UV 
measurements. Journal of Geophysical Research, 111, E09S06. https://doi.org/10.1029/2006JE002681

Piccialli, A., Vandaele, A. C., Trompet, L., Neary, L., Viscardy, S., Erwin, J. T., et al. (2021). Impact of gradients at the martian terminator on the retrieval of ozone from SPICAM/MEx. Icarus, 353, 113598. https://doi.org/10.1016/j.icarus.2019.113598

Pouvesle, N., Kippenberger, M., Schuster, G., \& Crowley, J. N. (2010). The interaction of $\mathrm{H}_{2} \mathrm{O}_{2}$ with ice surfaces between 203 and 233 K. Physical Chemistry Chemical Physics, 12, 15,544-15,550. doi:10.1039/c0cp01656j

Sehested, J., Nielsen, O. J., Egsgaard, H., Larsen, N. W., Petersen, T., Christensen, L. K., \& Wiegell, M. (1995). First direct kinetic study of isotopic enrichment of ozone, Journal of Geophysical Research, 100, 20,979-20,982.

Siskind, D. E., Stevens, M. H., Englert, C. R., \& Mlynczak, M. G. (2013). Comparison of a photochemical model with observations of mesospheric hydroxyl and ozone. Journal of Geophysical Research, 118, 195-207. https://doi.org/10.1029/2012JD017971

Smith, M. D., Daerden, F., Neary, L., \& Khayat, A. (2018). The climatology of carbon monoxide and water vapor on Mars as observed by CRISM and modeled by the GEM-Mars general circulation model. Icarus, 301, 117-131. https://doi.org/10.1016/j.icarus.2017.09.027

Stark, G., Yoshino, K., Smith, P. L., \& Ito, K. (2007). Photoabsorption cross section of CO2 between 106.1 and $118.7 \mathrm{~nm}$ at 295 and 195 K. Journal of Quantitative Spectroscopy \& Radiative Transfer, 103, 67-73. doi:10.1016/j.jqsrt.2006.07.001

Trainer, M. G., Wong, M. H., McConnochie, T. H., Franz, H. B., Atreya, S. K., Conrad, P. G., et al. (2019). Seasonal Variations in Atmospheric Composition as Measured in Gale Crater, Mars. Journal of Geophysical Research: Planets, 124, 3000-3024. https://doi.org/10.1029/2019JE006175 
Trokhimovskiy, A., Fedorova, A., Korablev, O., Montmessin, F., Bertaux, J.-L., Rodin, A., et al. (2015). Mars' water vapor mapping by the SPICAM IR spectrometer: five Martian years of observations. Icarus, 251, 50-64. http://dx.doi.org/10.1016/j.icarus.2014.10.007

Vals, M., Forget, F., Spiga, A., \& Millour, E. (2018). Impact of the refinement of the vertical resolution on the simulation of the water cycle by the martian LMD Global Climate Model. Paper presented at the European Planetary Space Congress, Vol. 12, EPSC2018-847, Berlin, Germany.

Vandaele, A. C., Lopez-Moreno, J.-J., Patel, M. R., Bellucci, G., Daerden, F., Ristic, B., et al. (2018). NOMAD, an integrated suite of three spectrometers for the ExoMars trace gas mission: technical description, science objectives and expected performance. Space Science Reviews, 214, 80. https://doi.org/10.1007/s11214-018-0517-2

Venot, O., Bénilan, Y., Fray, N., Gazeau, M.-C., Lefèvre, F., Es-sebbar, Et, et al. (2018) VUV-absorption cross section of carbon dioxide from 150 to $800 \mathrm{~K}$ and applications to warm exoplanetary atmospheres, Astronomy \& Astrophysics, 609, A34. doi: $10.1051 / 0004-6361 / 201731295$

Versick, S., Stiller, G. P., von Clarmann, T., Reddmann, T., Glatthor, N., Grabowski, U., \& al. (2012). Global stratospheric hydrogen peroxide distribution from MIPAS-Envisat full resolution spectra compared to Kasima model results. Atmospheric Chemistry and Physics, 12, 4923-4933. doi:10.5194/acp-12-4923-2012

Willame, Y., Vandaele, A. C., Depiesse, C., Lefèvre, F., Letocart, V., Gillotay, D., \& Montmessin, F. (2017). Retrieving cloud, dust and ozone abundances in the Martian atmosphere using SPICAM/UV nadir spectra. Planet. Space Sci. 142, 9-25. http: //dx.doi.org/10.1016/j.pss.2017.04.011 
Wolff, M. J., Clancy, R. T., Goguen, J. D., Malin, M. C., \& Cantor, B. A., (2010). Ultraviolet dust aerosol properties as observed by MARCI. Icarus, 208, 143-155. doi:10.1016/j.icarus.2010.01.010

Wolff, M. J., Clancy, R. T., Kahre, M. A., Haberle, R. M., Forget, F., Cantor, B. A., \& Malin, M. C. (2019). Mapping water ice clouds on Mars with MRO/MARCI. Icarus, 332, 24-49. https://doi.org/10.1016/j.icarus.2019.05.041

Yoshino, K., Sun, Y., Esmond, J. R., Parkinson, W. H., Ito, K., \& Matsui, T. (1996). Absorption cross section measurements of carbon dioxide in the wavelength region 118.7-175.5 nm and the temperature dependence. Journal of Quantitative Spectroscopy and Radiative Transfer, 55, 53-60. 